-

\title{
ANÁLISE DA EVOLUÇÃO DA ATIVIDADE EMPREENDEDORA NO BRASIL DE ACORDO COM O GLOBAL ENTREPRENEURSHIP MONITOR (GEM) ENTRE OS ANOS DE 2000 E 2013
}

DOI: 1014211/regepe33002

\author{
Vitor Koki da Costa Nogami - Universidade de São Paulo ${ }^{1}$ \\ Juliana Medeiros - Universidade Federal do Paraná ${ }^{2}$ \\ Valter da Silva Faia - Universidade Estadual de Maringá ${ }^{3}$
}

\begin{abstract}
Resumo: $O$ presente artigo tem o objetivo de investigar a evolução da atividade empreendedora no Brasil, com base nos relatórios do Global Intrapreneurship Monitor (GEM), no período de 2000 a 2013. A revisão da literatura está fundamentada na relação entre o crescimento econômico com a atividade empreendedora, bem como nas características empreendedoras orientadas pelo GEM. Para tanto, foram utilizados dados secundários dos relatórios do GEM entre o período compreendido de 2000 a 2013. Os resultados da pesquisa apontam que as principais características da atividade empreendedora no Brasil são: (a) altas e constantes taxas de empreendedorismo em relação aos outros países pesquisados; (b) o governo brasileiro, ao mesmo tempo em que apoia atividade com políticas públicas, dificulta o empreendedorismo com entraves tributários; (c) as mulheres cada vez mais se apresentaram como praticantes da atividade empreendedora; e (d) apesar de apresentar altas taxas de empreendedorismo, a atividade no Brasil se caracteriza por ter baixo índice de inovação. Ainda, é possível concluir que o crescimento econômico influencia positivamente a prática empreendedora, aumentando o poder de compra das pessoas, facilitando o acesso a financiamentos e gerando novas empresas. Porém, também se pode concluir que a desaceleração da economia ocasiona altas taxas de desemprego, fazendo com que as pessoas busquem alternativas de renda, como abrir o próprio negócio. Assim, uma economia frágil também influencia a atividade empreendedora. Como contribuição teórica, este artigo destaca a relação não exaustiva entre crescimento econômico e atividade empreendedora, que se caracteriza por ser positiva em alguns casos e negativa em outros, bem como apresenta um panorama abrangente destacando pontos importantes da atividade empreendedora brasileira nos últimos 14 anos. Como contribuição metodológica, o artigo utiliza-se de pesquisa documental em dados secundários de um projeto já conceituado e pouco utilizado em pesquisas acadêmicas, o GEM. Como contribuição gerencial, o artigo é um direcionador para políticas públicas.
\end{abstract}

Palavras-chave: Empreendedorismo, Atividade Empreendedora, Global Intrapreneurship Monitor (GEM).

\footnotetext{
${ }^{1}$ E.mail: vitornogami@gmail.com - Endereço: Avenida Professor Luciano Gualberto, 908, Butantã, São Paulo - SP, CEP: 05508-010.

${ }^{2}$ E.mail: julianamedeiros84@gmail.com

${ }^{3}$ E.mail: valterfaia@gmail.com
}

NOGAMI, V. K. C.; MEDEIROS, J.; FAIA, V. S. Análise da evolução da atividade empreendedora no Brasil de acordo com o Global Entrepreneurship Monitor (GEM) entre os anos de 2000 e 2013. Revista de Empreendedorismo e Gestão de Pequenas Empresas, v. 3, n.3, p. 31-76, 2014. 
ANALYSES OF THE EVOLUTION OF THE ENTREPRENEURSHIP ACTIVITY IN BRAZIL ACCORDING TO THE GLOBAL ENTREPRENEURSHIP MONITOR (GEM) BETWEEN THE YEARS 2000 AND 2013

Abstract: This paper aims to investigate the evolution of entrepreneurial activity in Brazil, based on reports from Global Entrepreneurship Monitor (GEM) from 2000 to 2013. The literature review is based on the relationship between economic growth with entrepreneurial activity; and entrepreneurial characteristics oriented by GEM. For this, it was used secondary data from the GEM reports between the years 2000 to 2013. The research results indicate that the main characteristics of entrepreneurial activity in Brazil are: (a) high and constant rates of entrepreneurship compared to the other countries researched, (b) the Brazilian government while supporting activity with public policy, difficult entrepreneurship with tax barriers; (c) women increasingly presented themselves as practitioners of entrepreneurial activity, and (d) despite having high rates of entrepreneurship, the activity in Brazil is characterized by having a low rate of innovation. It is still possible to conclude that economic growth positively influences entrepreneurial practice, increasing the purchasing power of the people, by facilitating access to financing and generating new business. However, it can also be concluded that the slowdown of the economy leads to high rates of unemployment, causing people to seek alternative sources of income, such as opening their own business. So a weak economy also influences entrepreneurial activity. As a theoretical contribution, this article highlights the non-exhaustive relationship between economic growth and entrepreneurial activity that is characterized by positive in some cases and negative in others, and presents a comprehensive overview highlighting important points of the Brazilian entrepreneurial activity in the last 14 years. As a methodological contribution, this paper uses documentary research on secondary data from a project already conceptualized and little used in academic research, the GEM. As a management contribution, this article is a guide to public policy.

Keywords: Entrepreneurship, Entrepreneurial Activity, Global Entrepreneurship Monitor (GEM).

\section{Introdução}

Os estudos na área de empreendedorismo buscam examinar como e por quem as oportunidades para criação de novos produtos ou serviços são descobertas, avaliadas e exploradas, bem como quais os efeitos de tais atividades empreendedoras (SHANE; VENKATARAMAN, 2000).

O empreendedorismo apresenta diversas interfaces com outras áreas do conhecimento. Uma delas é o crescimento econômico. Deste modo, realizar pesquisas no campo do empreendedorismo exige desenvoltura interdisciplinar (FONTENELE, 2010).

NOGAMI, V. K. C.; MEDEIROS, J.; FAIA, V. S. Análise da evolução da atividade empreendedora no Brasil de acordo com o Global Entrepreneurship Monitor (GEM) entre os anos de 2000 e 2013. Revista de Empreendedorismo e Gestão de Pequenas Empresas, v. 3, n.3, p. 31-76, 2014. 
A relação entre empreendedorismo e crescimento econômico é aparentemente direta, porém existem especificidades regionais que diferenciam 0 resultado empreendedor em diferentes localizações (JULIEN, 2010).

A contribuição da atividade empreendedora para o desenvolvimento econômico varia de acordo com o contexto em que ela ocorre. No entanto, a maior parte do desenvolvimento conceitual no campo do empreendedorismo tem ocorrido, ou assumido, em condições de mercados maduros e em países ricos (SMALLBONE; WELTER; ATELJEVIC, 2013). Portanto, o presente artigo pretende investigar quais são os desdobramentos da atividade empreendedora no crescimento econômico, especificamente no ambiente brasileiro.

Em regiões economicamente emergentes, como países da África, Ásia, Leste Europeu e da América Latina, o empreendedorismo apresenta papel crucial para o crescimento econômico e desenvolvimento social, contribuindo para o aumento do PIB, consumo e geração de emprego (VAN STEL et. al, 2005; PFEIFER; SARLIJA, 2010; SHANE, 2012).

Para ser considerado emergente, um país precisa obter esforços governamentais para implementação de reformas e crescimento econômico (SANDU, 2008). Duas características principais de um país emergente são a alta taxa de crescimento econômico com políticas governamentais para aquecer a economia e a adoção de sistema de mercado livre, caracterizando o Brasil como um país emergente.

Com o intuito de mensurar, analisar e comparar a atividade empreendedora entre os países, em 1999 foi criado Global Entrepreneurship Monitor (GEM), atualmente presente em mais de 50 países. Além de incorporar um caráter multi e interdimensional do empreendedorismo (GARTNER, 1985), o GEM não só analisa exclusivamente os negócios, mas também foca sua atenção para o indivíduo em suas interações com o ambiente que o cerca (SAUTET, 2013; SMALLBONE; WELTER; ATELJEVIC, 2013).

Deste modo, o conceito de empreendedorismo adotado pelo GEM visa captar toda e qualquer atividade que tenha característica de esforço autônomo para

NOGAMI, V. K. C.; MEDEIROS, J.; FAIA, V. S. Análise da evolução da atividade empreendedora no Brasil de acordo com o Global Entrepreneurship Monitor (GEM) entre os anos de 2000 e 2013. Revista de Empreendedorismo e Gestão de Pequenas Empresas, v. 3, n.3, p. 31-76, 2014. 
a abertura de nova atividade econômica, de modo a verificar em que medida determinada população é ou não empreendedora (FONTENELE, 2010).

Para isso, o principal indicador do GEM é a TEA - (Total Entrepreneurial Activity), que é taxa que indica qual o nível da prática empreendedora dos países. Ceteris paribus, países que apresentam aumento da taxa TEA, aumentam seus crescimentos econômicos (WONG; PING HO; AUTIO, 2005).

Tendo em vista que a pesquisa realizada pelo GEM já é tradicional e estabelecida por diversos países, seus dados podem ser considerados importantes indicadores como fonte de informação às instituições públicas e privadas, que estudam, investem, fomentam e praticam o empreendedorismo. Como apontado por Tanas e Audretsch (2011), a atividade empreendedora funciona como um catalisador para o progresso econômico, promovendo novas ideias e novas estruturas de mercado.

Já o estudo de Fontenele (2010) concluiu que a criação de empresas em diferentes países é influenciada pelo engajamento do governo no apoio ao empreendedorismo, por meio de incentivos de projetos de novas empresas, podendo ocorrer por mudanças nas leis e instituições, e no auxílio a gestão de pequenas empresas. Ademais, Sandu (2008) aponta a falta de pesquisas sobre o empreendedorismo nos países emergentes.

Por isso, diante deste cenário, é fundamental que no Brasil sejam intensificados os estudos em empreendedorismo, dada a relação desta prática com o crescimento econômico. É neste cenário, fundamentado nos relatórios do GEM, que o presente artigo se apresenta.

O Global Entrepreneurship Monitor (GEM) é um estudo organizado pela London Business School e Babson College que avalia anualmente a atividade empreendedora, aspirações e atitudes dos indivíduos em diversos países desde 1999. Apesar de o Brasil ter participado de 13 das 14 edições do estudo, a academia nacional utiliza de maneira bastante tímida esses dados para as pesquisas científicas no campo de empreendedorismo, podendo ser melhor explorados.

Em uma busca com a palavra chave "Global Entrepreneurship Monitor" nos resumos dos artigos de 136 periódicos nacionais, classificados entre $A 1$ e B3, na

NOGAMI, V. K. C.; MEDEIROS, J.; FAIA, V. S. Análise da evolução da atividade empreendedora no Brasil de acordo com o Global Entrepreneurship Monitor (GEM) entre os anos de 2000 e 2013. Revista de Empreendedorismo e Gestão de Pequenas Empresas, v. 3, n.3, p. 31-76, 2014. 
área de Administração (Apêndice 1), nos anais do EnANPAD de 1997 a 2013 e nos anais das oito edições do EGEPE (Encontro de Estudos sobre Empreendedorismo e Gestão de Pequenas Empresas), foram encontrados apenas 10 artigos envolvendo os relatórios do GEM e a atividade empreendedora no Brasil (BRUNEAU; MACHADO, 2006; CASTRO; GONÇALVES NETO, 2008; MEZA et al., 2008; SANTOS; FALCÃO, 2008; PEDROSO; MASSUKADO-NAKATANI; MUSSI, 2009; FONTELENE, 2010, FONTELENE; SOUSA; LIMA, 2011; NOGAMI; MACHADO, 2011; SOUZA; LOPEZ JÚNIOR, 2011; NOGAMI, 2012; NOGAMI; MACHADO, 2014).

Portanto, a lacuna que se pretende preencher é mesclar o conhecimento acadêmico sobre empreendedorismo com as evidências empíricas dos 14 relatórios do GEM acerca da atividade empreendedora brasileira.

Nessa linha, o presente artigo contribui com uma revisão e análise temporal da atividade empreendedora brasileira, sinalizando quais as características, desafios e conquistas da prática empreendedora. Os relatórios individuais são muito extensos e carregados de informações. Nesse sentido, o presente artigo contribui com o apontamento específico dos principais achados dos relatórios aliado a uma perspectiva temporal que busca esclarecer como a atividade empreendedora se constituiu, oferecendo fácil e rápida compreensão do conteúdo, bem como possibilitando a realização de projeções, tendo em vista a evolução passada com a conjuntura político-econômica presente.

Deste modo, a pergunta a ser respondida pelo presente trabalho é: como se caracteriza a atividade empreendedora brasileira nos últimos 14 anos (2000-2013) de acordo com os Relatórios do GEM? Assim, o estudo tem o objetivo de apontar quais foram as principais dificuldades, desafios, conquistas e oportunidades da atividade empreendedora de cada ano da pesquisa.

\section{Atividade empreendedora e o crescimento econômico}

O empreendedor assume papel central no crescimento da economia de um país. É como um protagonista que tem papel fundamental na evolução da vida

NOGAMI, V. K. C.; MEDEIROS, J.; FAIA, V. S. Análise da evolução da atividade empreendedora no Brasil de acordo com o Global Entrepreneurship Monitor (GEM) entre os anos de 2000 e 2013. Revista de Empreendedorismo e Gestão de Pequenas Empresas, v. 3, n.3, p. 31-76, 2014. 
empresarial e na substituição das empresas estabelecidas por novas organizações, capazes de explorar novas oportunidades e inovações. Reynolds (1999) corrobora esta associação entre a destruição criativa e o crescimento econômico, em outras palavras, comprova a relação direta entre a atividade empreendedora e o crescimento econômico.

Além de proporcionar crescimento econômico em um país, o GEM aponta que a atividade empreendedora também reflete no desenvolvimento social de uma região. Entretanto, a importância do empreendedorismo pode ser diferente, dependendo do estágio de desenvolvimento de cada região (JULIEN, 2010; SAUTET, 2013; SMALLBONE; WELTER; ATELJEVIC, 2013).

O pressuposto é que quanto mais entrantes ou ameaças de entrada em um mercado, maior a orientação das organizações para mais inovações e aumento de produtividade. Isso ocorre não somente porque são resultados diretos de inovações dos novos entrantes, mas também porque a ameaça de ser afetada por um novo e potencial concorrente faz com que as empresas estabelecidas sintam-se incentivadas para inovar e impedir a entrada de concorrentes (BARROS; PEREIRA, 2008). É bem verdade que o cenário de alta incerteza de um mercado proporciona a prática da inovação e da atividade empreendedora (WONG; PING HO; AUTIO, 2005).

Pesquisas apontam que a prática do empreendedorismo influencia no crescimento econômico (WONG; PING HO; AUTIO, 2005). Outras pesquisas apontam que um país crescente economicamente reflete em práticas empreendedoras (FONTENELE, 2010). Assim, há uma relação recíproca. De acordo com Câmara (2003), para se alcançar taxas de crescimento econômico em curto prazo, o incentivo ao empreendedorismo é uma alternativa eficiente.

Kardos (2012) evidenciou que países da União Europeia classificados como tendo alto nível de desenvolvimento sustentável, apresentaram níveis maiores de atividade empreendedora para micro e pequenas empresas (MPEs). Comparavelmente, os níveis de atividade empreendedora desses países foram superiores às taxas dos países com menor desenvolvimento e à taxa média da

NOGAMI, V. K. C.; MEDEIROS, J.; FAIA, V. S. Análise da evolução da atividade empreendedora no Brasil de acordo com o Global Entrepreneurship Monitor (GEM) entre os anos de 2000 e 2013. Revista de Empreendedorismo e Gestão de Pequenas Empresas, v. 3, n.3, p. 31-76, 2014. 
União Europeia. Do mesmo modo, os países com maior desenvolvimento também apresentaram índices de inovação superior.

Portanto, países em que as MPEs atuam de forma empreendedora e mais inovadora são melhores posicionadas nos rankings de desenvolvimento sustentável (KARDOS, 2012). Independentemente de saber qual variável é a dependente e qual é a independente, de acordo com esses autores, há correlação positiva entre crescimento econômico e atividade empreendedora.

Para Hafer (2013) a crença no valor do empreendedorismo como um fator no crescimento econômico é de longa data, pois modelos de crescimento econômico têm se expandido para incorporar vários medidas de empreendedorismo. Os investigadores têm procurado expandir a lista de fatores econômicos que podem contribuir para o crescimento econômico observado, sendo um deles o papel do empreendedorismo (HAFER, 2013). Isto levou a informações valiosas sobre o processo dinâmico pelo qual o crescimento econômico ocorre.

Holcombe (1998) argumenta que a atividade empreendedora, uma vez incluída no modelo de crescimento neoclássico padrão, completa o processo pelo qual os fatores de produção (capital, trabalho e tecnologia) interagem para proporcionar o crescimento econômico. Para o autor, o motor do crescimento econômico é o empreendedorismo, e não o avanço tecnológico ou o investimento em recursos humanos capital per se. Além do mais a atividade empreendedora preenche os detalhes institucionais para ajudar a tornar o processo de crescimento mais compreensível (HOLCOMBE, 1998, p. 60).

O empreendedorismo consiste nos comportamentos competitivos que impulsionam o processo de mercado (WONG; PING HO; AUTIO, 2005). Esta visão inclui a introdução de novas atividades econômicas para o mercado como um exemplo de empreendedorismo (DÍAZ-CASERO; DÍAZ-AUNIÓN; SÁNCHEZESCOBEDO, 2012).

Desta forma, o empreendedorismo se manifesta não só pela entrada de novas empresas no mercado, mas também por entradas inovadoras e imitativas em novos mercados por parte das empresas estabelecidas. A partir desta perspectiva, a inovação tecnológica também se caracteriza por uma forma de empreendedorismo.

NOGAMI, V. K. C.; MEDEIROS, J.; FAIA, V. S. Análise da evolução da atividade empreendedora no Brasil de acordo com o Global Entrepreneurship Monitor (GEM) entre os anos de 2000 e 2013. Revista de Empreendedorismo e Gestão de Pequenas Empresas, v. 3, n.3, p. 31-76, 2014. 
Outro componente relacionado com a atividade empreendedora e com o crescimento econômico é a variação da taxa de desemprego. Por um lado, o aumento do número de empreendedores diminui a taxa de desemprego (WONG; PING HO; AUTIO, 2005).

Segundo o anuário do SEBRAE (2012), o número de MPEs no Brasil apresentou um crescimento médio entre 2000 e 2011 de 3,7\% a.a. No mesmo período, o crescimento médio do número de empregados formais pelas mesmas empresas foi de 5,1\% a.a. O órgão destaca o bom desempenho das MPEs no período analisado e sua importância para a economia, já que em 2011, as empresas desse porte representaram $99 \%$ de todos os estabelecimentos, $51,6 \%$ dos empregos privados não agrícolas e formais, e aproximadamente $40 \%$ de toda a massa salarial.

Por outro lado, há uma corrente de autores que discordam da relação positiva direta entre crescimento econômico e atividade empreendedora. Esta corrente assume que a atividade empreendedora é impulsionada por economias frágeis onde as pessoas recorrem à abertura do próprio negócio como forma de obter renda, uma vez que não há emprego no mercado (ALVAREZ; BARNEY, 2014; McMULLEN, 2011). Se não houver investimento e incentivo no capital humano, no direito de propriedade e no capital financeiro, a atividade empreendedora não gera crescimento econômico, sendo uma ação emergencial para aquisição de renda, também chamada de autoemprego de subsistência (ALVAREZ; BARNEY, 2014, ACS, 2006).

Em países com economia ruim, as pessoas são muito limitadas dentro das empresas. O processo empreendedor acontece dentro de um contexto determinado de situações já conhecidas. É como se as oportunidades fossem locais e nunca estendem para além dos limites da comunidade ou da pequena cidade. Em muitos desses casos, o empreendedorismo é socialmente produtivo, mas não gera um nível de riqueza que elimine a pobreza (SAUTET, 2013).

De acordo com a pesquisa de Van Stel, Carree e Thurik (2005), também realizada com os dados do GEM, a atividade empreendedora por empreendedores nascentes e de gestores de empresas jovens afetam o crescimento econômico, mas

NOGAMI, V. K. C.; MEDEIROS, J.; FAIA, V. S. Análise da evolução da atividade empreendedora no Brasil de acordo com o Global Entrepreneurship Monitor (GEM) entre os anos de 2000 e 2013. Revista de Empreendedorismo e Gestão de Pequenas Empresas, v. 3, n.3, p. 31-76, 2014. 
esse efeito depende do nível de renda per capita. Isto sugere que o empreendedorismo tem um papel diferente nos países em diferentes estágios de desenvolvimento econômico.

O elevado índice de desemprego, principalmente nos grandes centros urbanos, leva um número maior de pessoas a buscar melhores meios de sobreviverem. Assim, essas pessoas consideram a possibilidade de iniciar seus próprios negócios. Em países menos desenvolvidos, onde existem maiores taxas de desemprego, segundo Barros e Pereira (2008), é sugerido que as políticas governamentais sejam intensificadas para aumentar o crescimento econômico por meio da atividade empreendedora e, consequentemente, diminuir as taxas de desemprego. Portanto a relação direta entre atividade empreendedora e crescimento econômico passa a se inverter.

Nesse sentido, pode-se concluir que o fortalecimento econômico propicia mais oportunidade para a atividade empreendedora e para o desenvolvimento de inovação. Por outro lado, as pessoas que vivem em países com economias pobres sofrem com altas taxas de desemprego e enxergam na atividade empreendedora uma oportunidade de renda, empreendendo então por necessidade.

A dicotomia oportunidade versus necessidade como motivação empreendedora é de longa data, contudo, não são dois conceitos mutualmente exclusivos. Nada impede que, tendo em vista uma situação de dificuldade financeira (motivado pela necessidade), um empreendedor desenvolva um produto inexistente e desejado pelo mercado, sendo algo inovador, sustentável, que gere empregos e renda para um país (motivado pela oportunidade).

Pfeifer e Sarlija (2010), utilizando os dados do GEM, apontam empiricamente que existe correlação significativa entre atividade empreendedora, desempenho empresarial e desenvolvimento econômico. Mas essa correlação depende da motivação se caracterizar por oportunidade ou por necessidade.

NOGAMI, V. K. C.; MEDEIROS, J.; FAIA, V. S. Análise da evolução da atividade empreendedora no Brasil de acordo com o Global Entrepreneurship Monitor (GEM) entre os anos de 2000 e 2013. Revista de Empreendedorismo e Gestão de Pequenas Empresas, v. 3, n.3, p. 31-76, 2014. 
Global Entrepreneurship Monitor (GEM)

Antes de iniciar a discussão sobre a atividade empreendedora no Brasil, fazse necessário estabelecer o que o próprio GEM considera como empreendedorismo. O modelo GEM aceita a natureza multifacetada do empreendedorismo, reconhecendo que uma série de condições ambientais afetam três componentes principais do empreendedorismo: atitudes, atividades e aspirações. Essa combinação dinâmica produz uma nova atividade econômica e socialmente importante, gerando empregos e riqueza.

O GEM está baseado em três objetivos principais: (a) medir as diferenças no nível de atividade empreendedora entre os países, identificando os diferentes tipos e fases do empreendedorismo; (b) descobrir os fatores que determinam em cada país seu nível de atividade empreendedora; e (c) identificar as políticas públicas que podem favorecer a atividade empreendedora local.

Como existem muitos países com características diferentes, o GEM de 2008 estabeleceu três categorias de países para agrupá-los de acordo com suas características econômicas e empreendedoras. Esta divisão é pertinente, uma vez que a economia regional de cada país proporciona características empreendedoras diferentes em suas respectivas regiões (JULIEN, 2010). O Brasil, segundo o GEM, se enquadra na segunda categoria:

- Empreendedorismo em países factor-driven: países com baixos níveis de desenvolvimento econômico que possuem tipicamente um grande setor agrícola, fornecendo subsistência para grande parte da população que, na sua maioria, ainda vive no campo;

- Empreendedorismo em países efficiency-driven: países que apresentam um alto crescimento no desenvolvimento econômico nos últimos anos, como fortalecimento do setor privado e a presença e incentivos públicos para o desenvolvimento da economia. Nesta categoria se enquadram os países emergentes;

NOGAMI, V. K. C.; MEDEIROS, J.; FAIA, V. S. Análise da evolução da atividade empreendedora no Brasil de acordo com o Global Entrepreneurship Monitor (GEM) entre os anos de 2000 e 2013. Revista de Empreendedorismo e Gestão de Pequenas Empresas, v. 3, n.3, p. 31-76, 2014. 
- Empreendedorismo em países innovation-driven: países ricos que possuem a economia desenvolvida, estabelecida e equilibrada, com investimento em pesquisa e desenvolvimento, inovação e alta tecnologia.

O processo empreendedor definido pelo GEM pode ser observado na Figura 1. O primeiro grupo de empreendedores é chamado de empreendedores potenciais, que ainda estão na fase do reconhecimento das necessidades ou ainda estão formulando a ideia inicial. Passando pelo processo de concepção do negócio, o empreendimento passa para a fase inicial, na qual os empreendedores são subdivididos conforme duas classificações: nascentes e novos.

Os empreendedores nascentes estão envolvidos na estruturação do negócio, sem que haja ainda qualquer pagamento de salário ou remuneração de capital próprio no período de 0 a 3 meses. Após o nascimento da empresa, chega-se a fase do novo negócio, no qual o empreendedor é seu proprietário e administrador. Nessa fase, o negócio é caracterizado pelo pagamento de salário e de pró-labore ou outra forma de remuneração aos proprietários, bem como pela duração mínima de 3 e máxima de 42 meses.

Por fim, depois do processo de persistência se alcança a etapa do estabelecimento, com empreendimento com mais de 42 meses de vida. Neste momento, é importante ressaltar que a TEA corresponde à soma das empresas nascentes com as empresas novas, ou seja, empresas de 0 a 42 meses de vida, conforme aponta a Figura 1.

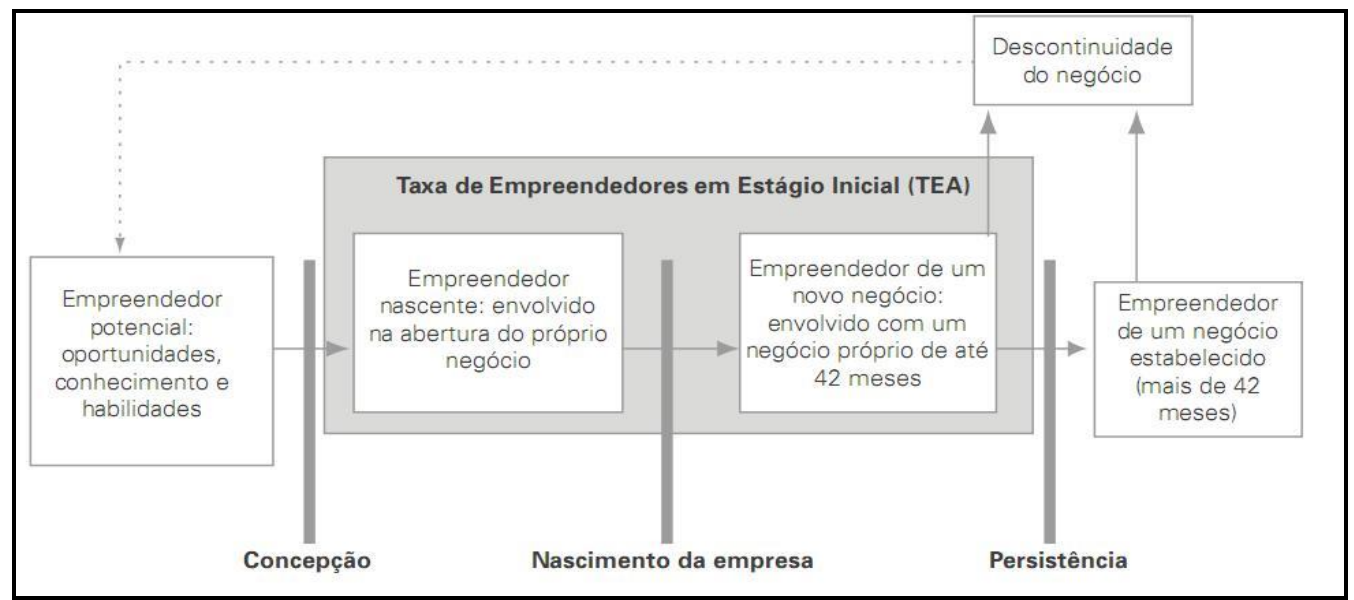

FIGURA 1 - O processo empreendedor e definições operacionais do GEM

Fonte: Relatório Executivo GEM-Brasil 2009.

NOGAMI, V. K. C.; MEDEIROS, J.; FAIA, V. S. Análise da evolução da atividade empreendedora no Brasil de acordo com o Global Entrepreneurship Monitor (GEM) entre os anos de 2000 e 2013. Revista de Empreendedorismo e Gestão de Pequenas Empresas, v. 3, n.3, p. 31-76, 2014. 
É pertinente discorrer sobre as lacunas que a pesquisa do GEM pretende preencher (STERNBERG; WENNEKERS, 2005). Apesar das críticas referentes à generalização do GEM, vale apontar que anteriormente às pesquisas do GEM, não havia parâmetros internacionais para uma comparação da atividade empreendedora entre diferentes países. Em segundo lugar, os dados estatísticos sobre empreendedorismo não eram constantemente atualizados e não apresentavam confiabilidade necessária para a execução de políticas públicas. Não existiam informações padronizadas sobre os processos de star-up empreendedor, as fontes existentes continham alguns indicadores, mas sempre apresentando lacunas.

Antes dos relatórios do GEM não era possível comparar as taxas da atividade empreendedora entre os países, muito menos fazer análises temporais como a que a será apresentada neste artigo.

\section{Método da pesquisa}

O presente estudo se caracteriza como exploratório e descritivo, por ter como objetivo, investigar os elementos de um fenômeno relacionando diferentes variáveis (GIL, 2002). Os dados utilizados para a presente pesquisa se caracterizam como secundários, referentes aos relatórios do GEM (Global Entrepreneurship Monitor), do ano 2000 até 2012, período em que o Brasil participou da pesquisa.

Foram utilizados diferentes indicadores para analisar os dados, o principal deles é a TEA (Total Entrepreneurship Activity), principal indicador do GEM, além da relação de gênero, oportunidade e necessidade, renda, taxa de inovação, faixa etária, entre outras. A cada novo relatório, havia muitas informações que se repetiam em relação aos anos anteriores, como também, em cada novo relatório, por vezes, eram acrescentados e retirados alguns indicadores. Por estes dois fatores, a apresentação e análise dos dados apresentam apenas os principais fatos referentes à atividade empreendedora em cada ano.

Os relatórios do GEM fornecem a cada ano mais e diferentes informações, tornando o tratamento dos dados um processo extenso e cuidadoso, visando à fidelidade dos resultados apresentados. Portanto, foram analisados todos os

NOGAMI, V. K. C.; MEDEIROS, J.; FAIA, V. S. Análise da evolução da atividade empreendedora no Brasil de acordo com o Global Entrepreneurship Monitor (GEM) entre os anos de 2000 e 2013. Revista de Empreendedorismo e Gestão de Pequenas Empresas, v. 3, n.3, p. 31-76, 2014. 
relatórios GEM-Brasil e todos os relatórios GEM Global para, além de confirmar e comparar as informações, fortalecer o embasamento do trabalho.

Então, o processo de captação dos dados, processamento e filtragem das informações ocorreu de forma que os resultados não se tornassem repetitivos, mas sim possuindo as informações marcantes de cada ano, para atingir o objetivo da pesquisa. Estes resultados são apresentados a seguir.

\section{Apresentação dos resultados}

O Gráfico 1 mostra a trajetória da TEA-Brasil de 2002 a 2013, comparativamente a taxa de empreendedores estabelecidos (TEE), considerando o percentual de empreendedores novos e já estabelecidos em relação a população entre 18 e 64 anos.

Inicialmente, destaca-se que o índice TEA-Brasil de 2013 foi $28,15 \%$ maior do que o índice registrado em 2002. Apesar de algumas oscilações do índice nesse período, em média, o nível da atividade empreendedora no Brasil cresceu no período analisado. Crescimento ainda maior foi registrado no nível de empreendedores estabelecidos.

Comparando o índice de 2013 com o índice de 2002, o crescimento foi de $97,45 \%$, praticamente dobrando o índice. O número de empreendimentos estabelecidos de um ano pode ser considerado como consequência do número de empreendimentos iniciais de até 3,5 anos anteriores. Entretanto, o ritmo de crescimento maior do índice TEE representa não só o crescimento no número de empreendimentos, mas também, uma redução na taxa de mortalidade dos empreendimentos novos.

NOGAMI, V. K. C.; MEDEIROS, J.; FAIA, V. S. Análise da evolução da atividade empreendedora no Brasil de acordo com o Global Entrepreneurship Monitor (GEM) entre os anos de 2000 e 2013. Revista de Empreendedorismo e Gestão de Pequenas Empresas, v. 3, n.3, p. 31-76, 2014. 
Empreendedores iniciais Empreendedores Estabelecidos

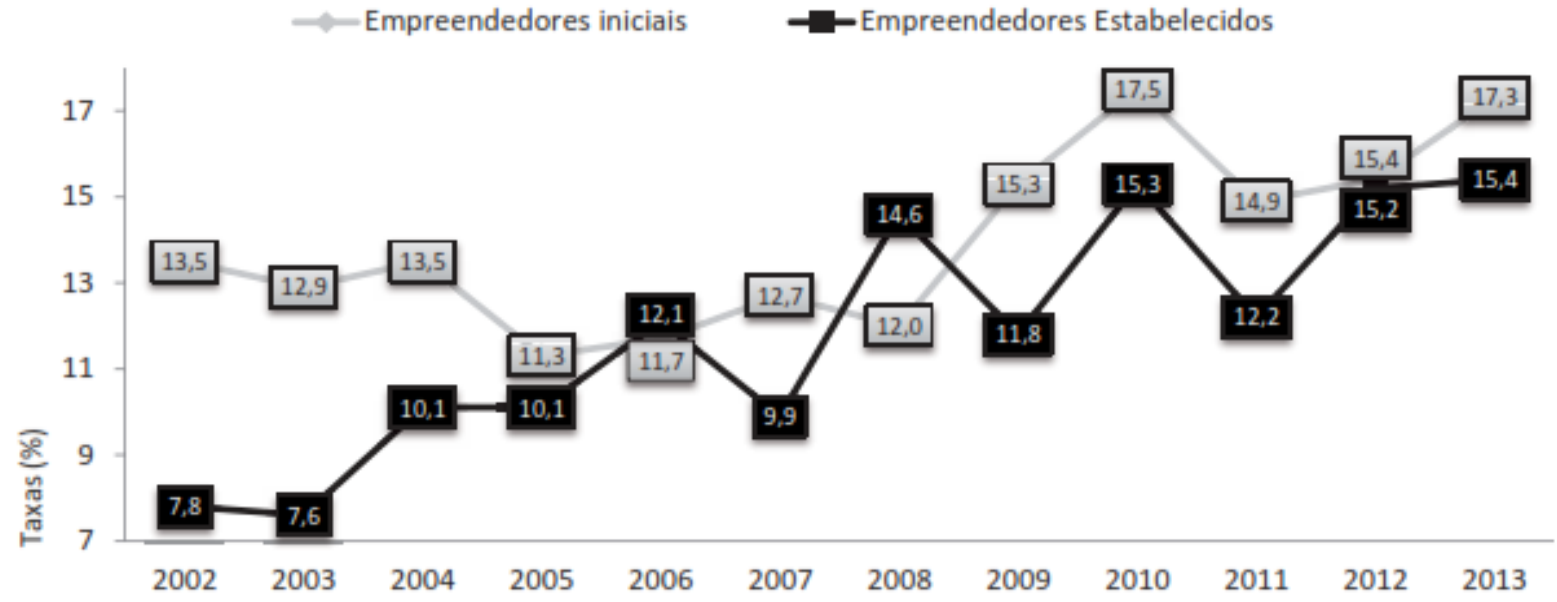

GRÁFICO 1 - Evolução da Total Entrepreneurship Activity (TEA) - Brasil

Fonte: Relatório Executivo GEM-Brasil 2013.

Entretanto, analisando mais cuidadosamente a variação ocorrida nos últimos anos, pode-se inferir que a crise mundial iniciada em 2008 afetou levemente a atividade empreendedora no Brasil (GEM-BRASIL, 2009). Esta crise sucumbiu o número de empregos em grandes organizações, aumentando a taxa de desemprego. Sendo assim, a partir de 2008, notou-se um considerável aumento no número de empresas iniciais.

Brasil no GEM 2000 - 20 países participantes

O ano de 2000 foi o primeiro em que o Brasil participou da pesquisa do GEM. Neste ano, os relatórios eram únicos e globais, mapeando a atividade empreendedora no mundo como um todo, portanto, não há um relatório específico do GEM Brasil 2000. Nos anos seguintes, já são editados relatórios especialmente para cada país, além do relatório global. Dentre os 21 países participantes da pesquisa em 2000, o Brasil é o que apresentou maior taxa de empresas nascentes e a terceira maior taxa de empresas novas, adquirindo a maior TEA (Total Entrepreneurship Activity), junção entre as duas primeiras taxas.

Um dado específico da pesquisa no Brasil aponta que a razão entre 0 empreendedorismo praticado por homens em relação ao praticado pelas mulheres é

NOGAMI, V. K. C.; MEDEIROS, J.; FAIA, V. S. Análise da evolução da atividade empreendedora no Brasil de acordo com o Global Entrepreneurship Monitor (GEM) entre os anos de 2000 e 2013. Revista de Empreendedorismo e Gestão de Pequenas Empresas, v. 3, n.3, p. 31-76, 2014. 
de 1,6 para1. Este fato é especial no Brasil, uma vez que nos outros países, a razão entre o empreendedorismo baseado no gênero (homem/mulher), na maioria das vezes, é de 2 para1 pelo menos, quando não é maior. Em outras palavras, as mulheres no Brasil mostraram-se com maior potencial para abrir uma empresa do que as mulheres nos outros países pesquisados, isso se repete nos anos seguintes.

Outra característica diferenciada da prática empreendedora no Brasil em relação aos demais países é a atividade voltada para a agricultura. Junto com a Índia, o Brasil foi classificado como um país com a economia direcionada para o agronegócio.

Brasil no GEM 2001 - 28 países participantes

Em 2001, o número de participantes da pesquisa aumentou e o Brasil deixou de possuir a maior taxa empreendedora (TEA). A Austrália e Coréia do Sul ultrapassaram o Brasil, e a entrada do México e Nova Zelândia deixaram o país em 5ำ no ranking geral do GEM. A perda do primeiro lugar no ranking da TEA não se deu apenas pelos novos entrantes na pesquisa ou pela evolução da taxa da Austrália e Coréia do Sul, mas também pela redução da taxa no Brasil, que caiu quase $1 \%$.

Um indicador acrescentado na pesquisa de 2001 é quanto à motivação para o empreendedorismo - oportunidade e necessidade. O empreendedorismo por oportunidade necessita de infraestrutura adequada com presença de investidores informais (angels) e facilidade nos processos (legais, fiscais e burocráticos) da abertura do negócio.

Já o empreendedorismo motivado pela necessidade, de forma geral, exige menos recursos e um nível menor de sofisticação operacional e tecnológica, muitas vezes atuando na informalidade (GEM-BRASIL, 2001). A pesquisa apontou que naquele ano, o empreendedorismo por oportunidade no Brasil foi de $60 \%$ e por necessidade de $40 \%$. Levando em consideração apenas o empreendedorismo por necessidade, o Brasil seria o terceiro no ranking entre os países pesquisados.

NOGAMI, V. K. C.; MEDEIROS, J.; FAIA, V. S. Análise da evolução da atividade empreendedora no Brasil de acordo com o Global Entrepreneurship Monitor (GEM) entre os anos de 2000 e 2013. Revista de Empreendedorismo e Gestão de Pequenas Empresas, v. 3, n.3, p. 31-76, 2014. 
Um aspecto negativo da atividade empreendedora no Brasil em 2001 foi quanto ao investimento informal. A taxa de business angel do Brasil era de 0,9\%, sendo a mais baixa de todos os países pesquisados. Tanto investimentos por angels quanto por crédito de financeiras e bancos, foram fatores que frearam a prática empreendedora, faltando também uma cultura de capital de risco entre os brasileiros.

Outro aspecto foi quanto à intervenção do governo. Esta intervenção, além de incentivar e estimular a atividade, também atrapalha quando exagera na burocracia, nos tributos e nas leis exigidas, que impedem o melhor desenvolvimento do empreendedorismo.

Brasil no GEM 2002 - 37 países participantes

Com mais duas posições perdidas no ranking, agora em 7ํ lugar, o Brasil fica atrás da Tailândia, Índia, Chile, Coréia, Argentina e Nova Zelândia. Tailândia e Chile participam pela primeira vez da pesquisa, Coréia e Nova Zelândia se mantêm na frente do Brasil, e Índia e Argentina sobem no ranking. Contudo, esta pequena redução detectada nos níveis de empreendedorismo no Brasil de certa maneira é consequência de um contexto político-econômico adverso que atingiu não apenas o Brasil, mas a economia Global como um todo.

Um indicador a ser observado mais uma vez na pesquisa é a relação da motivação para o empreendedorismo, por necessidade e oportunidade. Há uma distância grande entre estes dois indicadores. Considerando apenas o empreendedorismo por necessidade, o Brasil seria o $1^{\circ}$ no ranking. Considerando o aspecto oportunidade, o Brasil seria apenas o 16\%. Isto indica que a atividade empreendedora nacional está baseada mais na busca de recursos como fonte de renda familiar, do que na implementação de novas ideias, inovações, tecnologias, produtos e mercados.

Não diferente da opinião dos especialistas em empreendedorismo no mundo, os especialistas brasileiros concordam que políticas governamentais, educação e treinamentos são pontos fortes para o incentivo ao empreendedorismo (GEM-

NOGAMI, V. K. C.; MEDEIROS, J.; FAIA, V. S. Análise da evolução da atividade empreendedora no Brasil de acordo com o Global Entrepreneurship Monitor (GEM) entre os anos de 2000 e 2013. Revista de Empreendedorismo e Gestão de Pequenas Empresas, v. 3, n.3, p. 31-76, 2014. 
BRASIL, 2002). Porém, estes elementos não foram encontrados na pesquisa do GEM, sendo junto com o apoio financeiro, pontos fracos que não impulsionaram a atividade no Brasil nesse período.

Os pesquisados se mostraram altamente dependentes do governo para iniciar um processo de start-up, adotando uma postura passiva para o empreendedorismo. Junto a essa informação, o brasileiro também foi considerado pela pesquisa como tendo baixa capacidade de identificar e gerir os novos negócios.

Brasil no GEM 2003 - 31 países participantes

Em 2003, o Brasil sobiu uma posição no ranking (6), ficando atrás agora das estreantes Uganda e Venezuela, bem como das já estabelecidas Argentina, Chile e Nova Zelândia. Já é possível observar que o Brasil está sempre entre os primeiros no ranking da taxa TEA. No decorrer dos anos, alguns países entram, outros saem, mas o Brasil sempre se manteve entre os primeiros, sustentando uma taxa constante da atividade empreendedora.

Mais uma vez, vale salientar a diferença da TEA separando-se a atividade por gênero. Apenas entre os homens, o Brasil estaria em oitavo lugar no ranking, já com as mulheres, o Brasil passaria para quinto. Apesar de no Brasil o empreendedorismo ser ainda mais predominante entre os homens do que entre as mulheres, não se pode negar a importância que esta prática realizada por elas tem para a economia do país.

O fator renda mostrou um comportamento que merece atenção. É possível observar no Gráfico 2 que a taxa de empreendedorismo entre as pessoas com menor renda aumentou em 4 períodos de tempo consecutivamente, já a taxa entre as pessoas com maior renda diminuiu, se distanciando da curva de menor renda.

Conclui-se então, que as pessoas de menor renda enxergaram, através dos anos, uma possibilidade de aumentar seus recursos financeiros, apostando no próprio negócio. Já as pessoas com maior renda podem ter se acomodado, preferindo talvez outras formas de aplicação dos recursos.

NOGAMI, V. K. C.; MEDEIROS, J.; FAIA, V. S. Análise da evolução da atividade empreendedora no Brasil de acordo com o Global Entrepreneurship Monitor (GEM) entre os anos de 2000 e 2013. Revista de Empreendedorismo e Gestão de Pequenas Empresas, v. 3, n.3, p. 31-76, 2014. 


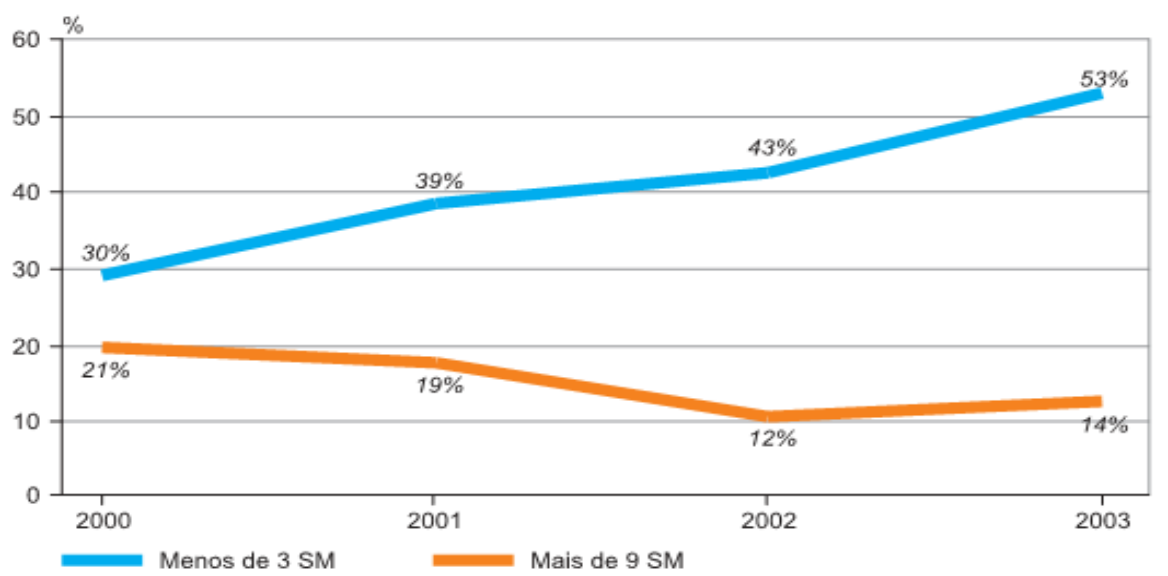

GRÁFICO 2 - Evolução da atividade empreendedora em relação à renda Fonte: Relatório Executivo GEM-Brasil 2003.

A motivação para o empreendedorismo apresentou um comportamento diferente nos 3 anos que entraram nos indicadores do GEM. Em 2001, o empreendedorismo por oportunidade foi maior do que o por necessidade (OP 8,5/NE $5,7)$. Em 2002, a proporção muda e o empreendedorismo por necessidade passa a ser maior do que por oportunidade (OP 5,8/NE 7,5). Em 2003, a empreendedorismo por oportunidade volta a apresentar maior taxa do que o por necessidade (OP 6,9/NE 5,5).

Uma possível justificativa para este fenômeno é que em 2002, o Brasil passou por uma crise cambial, aumentando o número de desempregados e, consequentemente, de empreendedores por necessidade (GEM-BRASIL, 2003).

Brasil no GEM 2004 - 34 países participantes

Voltando a $7^{0}$ posição, o Brasil fica atrás dos estreantes: Peru, Equador e Jordânia, além de Uganda, Nova Zelândia e Islândia que sobem algumas posições. Ainda apresentando alto nível de empreendedorismo por necessidade em relação aos outros países, o relatório de 2004 aponta também que 98\% das microempresas no Brasil são informais, corroborando a informação da presença de barreiras legais e tributárias para a formalização e criação de novos negócios.

De maneira geral, 3 fatores foram os principais limitadores para a atividade empreendedora no Brasil neste ano: apoio financeiro, políticas governamentais e 
educação e treinamento. As dificuldades em obter apoio financeiro ocorrem principalmente pelas exigências de garantias na concessão de empréstimos e da falta de informação, o que gera fortes barreiras aos negócios em suas fases iniciais. Neste caso, a elaboração de um bom plano de negócios poderia ser determinante para aquisição de financiamento (GREATTI; PREVIDELLI, 2007).

Nas entrevistas com especialistas, foi detectada falta de integração dos programas governamentais. Entretanto, alguns programas foram avaliados como incentivadores do empreendedorismo, destacando-se os projetos: apoio a exportações, apoio aos arranjos produtivos locais, os parques tecnológicos e incubadoras. Ou seja, o governo brasileiro ainda se caracteriza por estimular o empreendedorismo com programas de incentivo e também por desacelerar a atividade pela falta de integração e altos tributos.

A escolaridade do empreendedor no Brasil reflete a conjuntura educacional no país e ainda não foram atingidos no país os níveis educacionais das nações de maior desenvolvimento econômico, tanto em quantidade quanto em qualidade. Alguns dados demonstram esta informação: $97 \%$ das crianças estão na escola, porém, apenas $9 \%$ dos jovens entre 17 e 24 anos frequentam as universidades (GEM-BRASIL, 2004).

Brasil no GEM 2005 - 35 países participantes

Se mantendo na $7^{\circ}$ posição, o Brasil demonstra sua continuidade da atividade empreendedora. Os líderes do ranking desta vez não são mais os estreantes. Entre os 7 primeiros, apenas a Jamaica entrou na pesquisa neste ano. Vale ressaltar a permanência da Nova Zelândia e a evolução de China, Estados Unidos, Venezuela, e Tailândia.

Apresentando uma postura diferente das encontradas nos outros anos, em 2005, foi identificado maior apoio governamental à atividade empreendedora. $O$ projeto Juro Zero foi concebido pela FINEP e pelo Ministério da Ciência e Tecnologia para promover o crescimento das empresas de alto potencial. O programa apoia

NOGAMI, V. K. C.; MEDEIROS, J.; FAIA, V. S. Análise da evolução da atividade empreendedora no Brasil de acordo com o Global Entrepreneurship Monitor (GEM) entre os anos de 2000 e 2013. Revista de Empreendedorismo e Gestão de Pequenas Empresas, v. 3, n.3, p. 31-76, 2014. 
financeiramente as PMEs com base em tecnologias inovadoras e fornece a ausência ou a redução de taxas de juros (GEM-BRASIL, 2005).

Um fator que se fortalece na característica da atividade empreendedora no Brasil em 2005 é a atuação em mercados já conhecidos, replicando produtos e serviços, tendo assim, baixo nível de inovação e tecnologia (GEM-BRASIL, 2005).

Brasil no GEM 2006 - 42 países participantes

Em 2006, o Brasil caiu para 10ำ posição em relação à taxa TEA. Como ocorrem em todos os anos, as primeiras posições são conquistadas pelos estreantes, como Colômbia, Filipinas, Indonésia e Uruguai. As relações que chamaram a atenção nos primeiros anos dos relatórios se mantêm, como o empreendedorismo praticado por homens e mulheres, e o empreendedorismo motivado por oportunidade e necessidade.

Como citado no tópico 'C', referente ao ano de 2002, o brasileiro foi considerado como tendo baixa capacidade de identificar e gerir novos negócios. Já no relatório de 2006, a afirmação é outra: "o empreendedor brasileiro, de forma geral, reconhece boas oportunidades para empreender, sendo os principais estímulos à abertura de negócios, a busca por uma maior independência profissional e o aumento da renda pessoal." (GEM-BRASIL, 2006 p. 140).

Porém, a TEA se mantém relativamente constante em relação aos anos anteriores. Provavelmente, o discurso dos entrevistados (população adulta e especialista) mudou pelo fato da economia ter se estabilizado ou pelo governo ter criado alguns incentivos para a atividade, contudo, a TEA 2002 é maior do que a TEA 2006.

Brasil no GEM 2007 - 42 países participantes

$\mathrm{Na} 9^{\circ}$ posição, é possível afirmar que o Brasil em 8 anos de pesquisa apresenta uma taxa constante e está entre as economias que mais possui atividade empreendedora no mundo. Como é de se esperar, uma estreante entre as primeiras,

NOGAMI, V. K. C.; MEDEIROS, J.; FAIA, V. S. Análise da evolução da atividade empreendedora no Brasil de acordo com o Global Entrepreneurship Monitor (GEM) entre os anos de 2000 e 2013. Revista de Empreendedorismo e Gestão de Pequenas Empresas, v. 3, n.3, p. 31-76, 2014. 
a República Dominicana, e também como já acontece em todos os anos, os países da América Latina, sempre estão entre os melhores classificados no quesito TEA (8 entre os 11 primeiros colocados são países Latino-Americanos).

Uma análise realizada na pesquisa de 2007 é quanto à situação laboral do empreendedor brasileiro. O trabalhador assalariado formal tem assumido gradativamente a função de trabalhador empreendedor, desenvolvendo tarefas características do empreendedor e também assumindo riscos de atividades empreendedoras.

A maioria das microempresas brasileiras se mantém na informalidade, principalmente pelos custos altos e pelo longo tempo necessário para a legalização. Os altos encargos sociais e fiscais de operação para regularização e registro de uma empresa também não auxiliam. É observada ainda, uma tendência emergente do trabalho da dona de casa com os filhos que busca na base da informalidade compatibilizar o trabalho doméstico com atividades que completam a renda familiar. O jovem que assume um novo perfil no mercado de trabalho cria e recria sua condição profissional, como intraempreendedor em uma organização, como empreendedor em uma microempresa, como terceirizado especializado ou mesmo desenvolvendo uma atividade empreendedora como trabalhador autônomo (GEMBRASIL, 2007).

Cabe ressaltar e voltar à discussão sobre gênero, pelo fato de que pela primeira vez, a taxa de empreendedorismo praticado por mulheres ultrapassou a a dos homens em todos os anos da pesquisa GEM, como mostra a Tabela 1. Estes índices apresentaram aproximação desde o início das pesquisas.

Já na Tabela 2 é possível concluir que a necessidade é o principal fator de motivação para a mulher iniciar um negócio. Enquanto 38\% dos homens empreendem por necessidade, essa proporção aumenta para 63\% para as mulheres. Esses dados indicam que as mulheres buscam alternativa de empreendimentos para complementar a renda familiar ou ainda porque nos últimos anos elas vêm assumindo cada vez mais o sustento do lar como chefes da família (MACHADO, 2009).

NOGAMI, V. K. C.; MEDEIROS, J.; FAIA, V. S. Análise da evolução da atividade empreendedora no Brasil de acordo com o Global Entrepreneurship Monitor (GEM) entre os anos de 2000 e 2013. Revista de Empreendedorismo e Gestão de Pequenas Empresas, v. 3, n.3, p. 31-76, 2014. 
TABELA 1: Empreendedores Iniciais por Gênero no Brasil (2001 - 2007)

\begin{tabular}{|c|c|c|c|c|c|c|c|}
\hline & 01 & 02 & 03 & 04 & 05 & 06 & 07 \\
\hline $\mathrm{H}$ & 70,9 & 57,6 & 53,2 & 56,6 & 50 & 56,2 & 47,6 \\
\hline $\mathrm{M}$ & 29,1 & 42,4 & 46,8 & 43,4 & 50 & 43,8 & 52,4 \\
\hline
\end{tabular}

Fonte: Relatório Executivo GEM-Brasil 2007.

\section{TABELA 2: Empreendedores Iniciais por motivação segundo gênero no Brasil}

\begin{tabular}{cccc}
\hline & TEA & Oportunidade & Necessidade \\
\hline $\mathrm{H}$ & 48 & 54 & 38 \\
$\mathrm{M}$ & 52 & 46 & 63 \\
\hline
\end{tabular}

Fonte: Relatório Executivo GEM-Brasil 2007.

Por fim, ainda no relatório de 2007, é possível inferir que as condições culturais, educacionais e políticas não favorecem e nem estimulam o jovem brasileiro a iniciar um empreendimento independente ou manter seu próprio empreendimento com objetivos de longo prazo.

Devido aos baixos incentivos à prática empreendedora inovadora, e pelo empreendedorismo por necessidade ser efetivo no país, o empreendedorismo schumpteriano, que propõe um mercado, produto ou empreendimento inovador, não acontece no Brasil. Talvez, isto faça com que alguns pesquisadores considerem o Brasil um país empreendedor, por ter altas taxas de novas empresas e outros considerem um país pouco empreendedor, por não ocorrer grandes revoluções oriundas destas atividades.

Brasil no GEM 2008 - 43 países participantes

Pelo fato de haver muitas diferenças econômicas, sociais e políticas entre os países pesquisados pelo GEM, neste ano, realizou-se uma divisão para agrupar os países com características similares: factor driven, efficiency driven e innovation driven, como apresentado anteriormente no referencial teórico. No Gráfico 3 é possível observar quais países pertencem a cada grupo, e a posição do Brasil dentro do seu grupo, em $8^{\circ}$ lugar, e no geral, em $13^{\circ}$.

NOGAMI, V. K. C.; MEDEIROS, J.; FAIA, V. S. Análise da evolução da atividade empreendedora no Brasil de acordo com o Global Entrepreneurship Monitor (GEM) entre os anos de 2000 e 2013. Revista de Empreendedorismo e Gestão de Pequenas Empresas, v. 3, n.3, p. 31-76, 2014. 


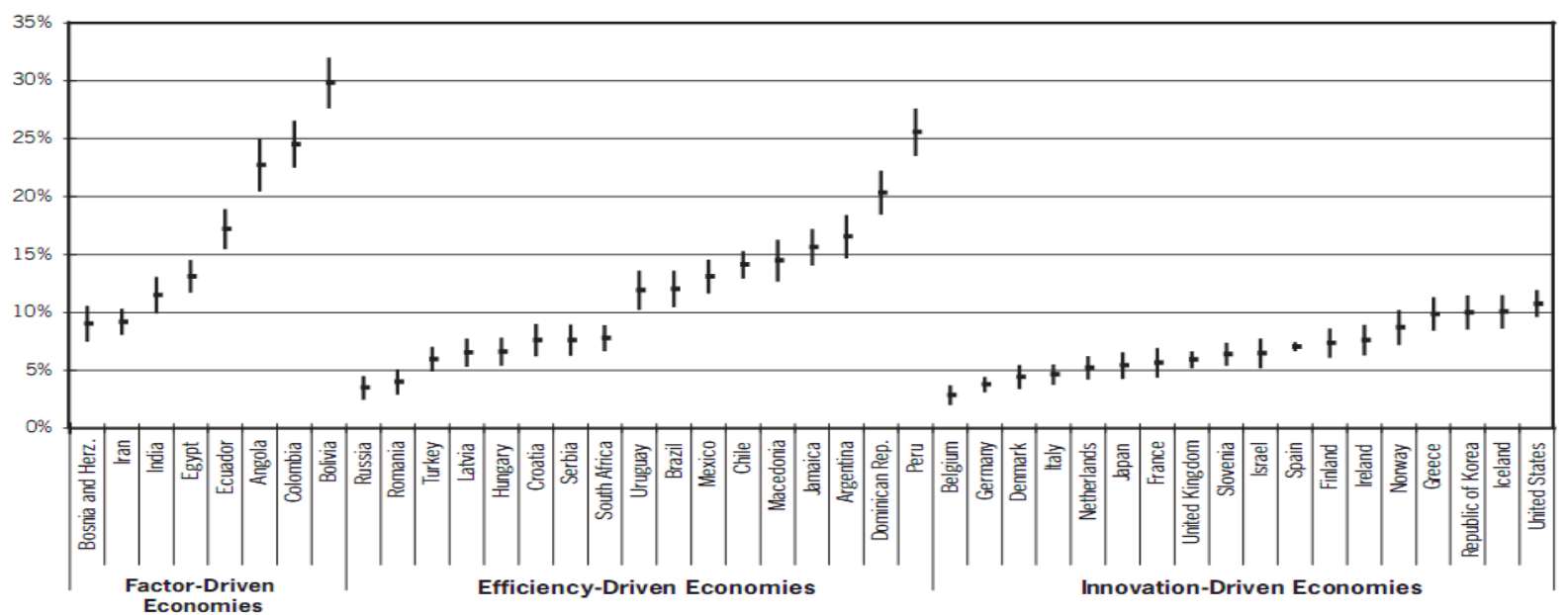

GRÁFICO 3 - TEA (Total Entrepreneurship Activity) dos países participantes do GEM 2008 divididos em 3 categorias

Fonte: Relatório Executivo GEM-Brasil 2003.

Levando-se em consideração novas tecnologias, empreendimentos com produtos, mercados inovadores e o empreendedorismo por oportunidade, o relatório GEM-Brasil 2008 corrobora a hipótese levantada no tópico anterior (5.8 Brasil no GEM 2007): O Brasil é um país que tem grande número de novos negócios, mas estes negócios não são inovadores e não utilizam novas tecnologias.

No relatório de 2008, este fato é bastante evidente, como demonstram alguns índices de acordo com a pesquisa:

- $84 \%$ dos empreendedores só lançam produtos já conhecidos no mercado;

- $65 \%$ têm muitos concorrentes;

- $98 \%$ utilizam tecnologias disponíveis há mais de um ano;

- $85 \%$ não possuem expectativa de exportar seus produtos;

- 45\% abrem suas empresas para garantir o próprio emprego, sem expectativa de gerarem novos empregos dentro de cinco anos;

- $78,3 \%$ não esperam gerar mais do que cinco empregos (normalmente de familiares);

- $60 \%$ desenvolvem atividades orientadas aos consumidores finais em atividades de prestação de serviços pessoais de baixa qualificação. 
Outro dado que marca a pesquisa de 2008 é a grande participação de jovens (18-24 anos) na atividade empreendedora no Brasil, em relação a outros países. No Brasil, menos de $25 \%$ das novas empresas são criadas por jovens, mas se considerar apenas esta faixa de idade, no mundo, o Brasil seria o $3^{\circ}$ no ranking. Ainda quanto à faixa etária, o Brasil quase não possui empreendimentos abertos por pessoas acima de 55 anos.

Por fim, esta edição apresenta o intraempreendedor, que para o GEM é considerado como: (i) criador de novos negócios dentro de uma empresa já existente; (ii) agente de mudança das ideias centrais que fundaram uma organização a partir da renovação de suas estratégias; e (iii) inovador, compreendendo a criação de novos produtos, serviços e mercados.

A pesquisa GEM Brasil 2008, identificou que 74\% das pessoas empregadas em tempo integral, não atuam em empresas de grande porte (onde geralmente ocorre o intraempreendedorismo) e 55\% desenvolvem novas atividades empresariais relacionadas ao processo de gestão, tais como liderança em novas modalidades de trabalho e programas de melhoria de processos, e não em novos produtos e mercados, que deveria ser o papel intraempreendedor.

Brasil no GEM 2009 - 54 países participantes

Em 2009, o Brasil apresentou a TEA de 15,32, e ficou na 6 posição dentro do grupo efficiency driven e em $13^{\circ}$ no geral. Uma explicação para o aumento considerável desta taxa neste ano pode ser a valorização e o elevado status que a carreira empreendedora tem apresentado perante a sociedade brasileira, criando um valor culturalmente favorável à adesão a esse tipo de atividade por parte de uma parcela da população.

Além disto, soma-se o fato de que 2009 foi um ano em que a ameaça ao emprego se deu de forma retumbante, com inúmeras notícias de demissões em larga escala e com setores industriais cortando muitos postos de trabalho. Importante ressaltar que neste mesmo ano também ocorreu a transferência de renda para as classes menos favorecidas via programas de auxílio, como as bolsas família

NOGAMI, V. K. C.; MEDEIROS, J.; FAIA, V. S. Análise da evolução da atividade empreendedora no Brasil de acordo com o Global Entrepreneurship Monitor (GEM) entre os anos de 2000 e 2013. Revista de Empreendedorismo e Gestão de Pequenas Empresas, v. 3, n.3, p. 31-76, 2014. 
e outras do gênero, gerando maior poder aquisitivo para a base da pirâmide (PONCHIO; ARANHA; TODD, 2006). De alguma forma estes fatores podem ter induzido uma grande quantidade de pessoas a aderir ao empreendedorismo como forma de proteção contra esta instabilidade da economia, provavelmente reflexo da crise mundial de 2008.

Quanto ao gênero, em 2007, as mulheres, pela primeira vez, apresentaram maior TEA do que os homens. Em 2008, os homens voltaram a ficar na frente e em 2009, as mulheres mais uma vez se apresentaram como maioria no quesito atividade empreendedora. Porém, como em anos anteriores, a atividade empreendedora para as mulheres se caracterizou por necessidade para completar a renda familiar, enquanto os homens praticam mais o empreendedorismo por oportunidade.

Alguns indicadores importantes ainda tendem a se manter baixos no Brasil. São os relacionados às características inovadoras e tecnológicas dos empreendimentos: que apresentam baixa capacidade de exportação, produtos que não são novos, possuir muitos concorrentes, não empregam muitas pessoas e a baixa qualificação. Quanto aos investidores informais, o Brasil continua sem esta cultura que alavanca a TEA de muitos outros países. Em relação a este indicador, o país é o último colocado.

Brasil no GEM 2010 - 59 países participantes

Em 2010 o Brasil melhorou sua posição no ranking mundial, sendo o 10응 colocado. Com 17,50\% de taxa TEA, em 2010, o Brasil atingiu seu maior índice. Dentro do grupo efficiency-driven, o país também melhorou sua posição, ocupando a 4ª posição, atrás do Peru (27,2\%), Equador (21,3\%) e da Colômbia (20,6\%). Vale destacar que apenas países da América Latina atingiram taxas superiores à brasileira entre os países efficiency-driven.

Fazendo outra comparação, agora entre os países membros do G20, o Brasil é o que possui maior taxa TEA, seguido pela China $(14,4 \%)$ e Argentina $(14,2 \%)$. Vale ressaltar que dentre os 20 países, 17 participaram da pesquisa em 2010 .

NOGAMI, V. K. C.; MEDEIROS, J.; FAIA, V. S. Análise da evolução da atividade empreendedora no Brasil de acordo com o Global Entrepreneurship Monitor (GEM) entre os anos de 2000 e 2013. Revista de Empreendedorismo e Gestão de Pequenas Empresas, v. 3, n.3, p. 31-76, 2014. 
Dentre os países do BRIC, o Brasil também apresenta maior taxa, pois a China possui TEA de 14,4\%, a Rússia possui 3,9\% e a Índia, apesar de não ter participado da pesquisa nos últimos 2 anos, apresentou taxas menores que a brasileira em suas participações, com 11,5\% na última participação (2008).

Observando a relação de empreendimentos abertos por necessidade e por oportunidade, é possível apontar que a conjuntura econômica influência a taxa (GEM-BRASIL, 2010). Em 2010, houve diminuição da taxa de desemprego no país e aumento de empregados registrados. Consequentemente, o número de negócios abertos por necessidade diminuiu, aumentando a probabilidade do aumento de negócios serem abertos por oportunidade. Este dado pode ser corroborado observando a última coluna da direita na Tabela 3, onde o índice da TEA, baseada na razão da atividade empreendedora por oportunidade e necessidade, aumenta conforme as características econômicas dos países.

TABELA 3: Total Entrepreneurship Activity (TEA) por Necessidade e Oportunidade

\begin{tabular}{lccc}
\hline & Necessidade & Oportunidade & $\begin{array}{c}\text { Razão Oportunidade e } \\
\text { Necessidade }\end{array}$ \\
\hline Todos & 3,6 & 7,8 & 2,17 \\
Factor-Driven & 7,7 & 14,3 & 1,86 \\
Efficiency-Driven & 3,6 & 7,8 & 2,17 \\
Innovation-Driven & 1,1 & 3,9 & 3,55 \\
Brasil & 5,4 & 11,9 & 2,20 \\
\hline
\end{tabular}

Fonte: Relatório Executivo GEM-Brasil 2010.

Todavia, nos três grupos, a atividade empreendedora baseada na oportunidade é maior que a atividade empreendedora baseada na necessidade. Este fenômeno seria aceitável nos países innovation-driven, uma vez que possuem economia estabelecida e fortalecida. Em países que possuem dificuldades financeiras, teoricamente, a atividade empreendedora baseada na necessidade deveria ser predominante.

Este resultado pode ser devido à maneira como são coletados os dados, uma vez que é perguntado ao entrevistado se o seu negócio foi aberto motivado pela necessidade ou pela oportunidade. Para não demonstrar que possuem dificuldades financeiras, os respondentes podem fundamentar suas respostas na oportunidade.

NOGAMI, V. K. C.; MEDEIROS, J.; FAIA, V. S. Análise da evolução da atividade empreendedora no Brasil de acordo com o Global Entrepreneurship Monitor (GEM) entre os anos de 2000 e 2013. Revista de Empreendedorismo e Gestão de Pequenas Empresas, v. 3, n.3, p. 31-76, 2014. 
Para finalizar a análise do ano de 2010, a Tabela 4 corrobora as observações do relatório GEM-Brasil 2008 (tópico 5.9) apontando que mesmo o Brasil sendo um dos países mais empreendedores do mundo, a inovação não é característica destes novos empreendimentos. De maneira geral, os empreendimentos abertos no Brasil não possuem tecnologias novas, apresentam grande quantidade de concorrentes no mercado e não têm novidades nos produtos e serviços.

\begin{tabular}{cc} 
TABELA 4: Conhecimento do Produto ou Serviço \\
\hline Produto ou Serviço & Proporção(\%) \\
\hline Novo para Todos & 7,5 \\
Novo para Alguns & 9,3 \\
Ninguém considera Novo & 83,2 \\
\hline
\end{tabular}

Fonte: Relatório Executivo GEM-Brasil 2010.

Quanto ao gênero, as posições se invertem novamente, mas com diferenças mínimas. O empreendedorismo praticado por homens atingiu 50,7\% e o praticado por mulheres, 49,3\%. Apresentando pequenas diferenças entre a taxa TEA desde 2005, a mulheres legitimaram seu espaço no mercado no quesito abertura de novo negócios.

Brasil no GEM 2011 - 54 países participantes

Em 2011, o Brasil se manteve em $10^{\circ}$ colocado dentro do grupo efficiencydriven e foi o $13^{\circ}$ no ranking geral. Este ano ficou marcado pela baixa participação de países factor-driven na pesquisa, que consequentemente proporciona uma melhora no ranking dos países efficiency-driven, no que diz respeito à taxa TEA. O que ainda é marcante na população brasileira é o baixo encorajamento social para as pessoas correrem riscos de assumir o próprio negócio. A estabilidade de ter um emprego ainda é mais valorizada do que os riscos embutidos na abertura de um negócio próprio. Outro fator negativo ainda são as taxas de juros. Apesar de terem sido baixadas, este fator está longe de ser favorável ao empreendedor no país.

Em termos gerais, a pesquisa de 2011 revela que a maioria da fatia empreendedora é jovem, possuindo entre 25 a 34 anos de idade e com renda alta. $O$ que chama atenção é a correlação negativa entre o grau de escolaridade e a

NOGAMI, V. K. C.; MEDEIROS, J.; FAIA, V. S. Análise da evolução da atividade empreendedora no Brasil de acordo com o Global Entrepreneurship Monitor (GEM) entre os anos de 2000 e 2013. Revista de Empreendedorismo e Gestão de Pequenas Empresas, v. 3, n.3, p. 31-76, 2014. 
atividade empreendedora. Este dado revela que menor escolaridade proporciona maior abertura de novos negócios. Isto, consequentemente, explica o baixo índice de inovação nesses novos negócios e a predominância da necessidade como motivação para a prática empreendedora. Outro fator que explica este fenômeno curioso é a baixa qualificação da mão de obra nacional. Assim, os poucos profissionais com boa qualificação são requisitados por grandes empresas.

Em relação ao gênero, a mulher brasileira continua se destacando no cenário mundial, sendo o $4^{\circ}$ país onde as mulheres mais empreendem. O relatório destaca três fatores para este indicador alto. Em primeiro lugar, muitas mulheres criam seus filhos sozinhas e precisam trabalhar para sustentar a família. Segundo, a mulher ainda não é remunerada igualmente aos homens, elas possuem em média um salário $30 \%$ menor do que o deles. Por fim, a mulheres tem mais tempo de estudo do que os homens, podendo assim, utilizar desta vantagem para gerenciarem seus negócios.

Existem ainda alguns incentivos específicos para atividades empreendedoras sustentáveis. Instituições de ensino superior, públicas e privadas, grandes bancos, públicos e privados, e grandes empresas privadas que realizam com frequência concursos de planos de negócios que envolvem a sustentabilidade para apoio e financiamento. A vantagem destas práticas não é só mais uma empresa no mercado aumentando o PIB nacional e gerando empregos, mas sim uma empresa a mais preocupada com questões ambientais. Estes concursos poderiam ser mais incentivados por políticas públicas específicas em prefeituras, ONGs e agências reguladoras, por exemplo.

Brasil no GEM 2012 - 67 países participantes

Em 2012, o Brasil foi o $9^{\circ}$ no ranking do grupo efficiency-driven e $16^{\circ}$ no ranking geral. Entretanto, considerando a taxa total de empreendedorismo, 30,2\% da população brasileira de 18 a 64 anos se encontrava envolvida com algum tipo de empreendimento, posicionando o país em 10 no ranking mundial. Como destacado pelo próprio relatório, esse número ressalta a importância econômica e social do

NOGAMI, V. K. C.; MEDEIROS, J.; FAIA, V. S. Análise da evolução da atividade empreendedora no Brasil de acordo com o Global Entrepreneurship Monitor (GEM) entre os anos de 2000 e 2013. Revista de Empreendedorismo e Gestão de Pequenas Empresas, v. 3, n.3, p. 31-76, 2014. 
empreendedorismo no país. Quando questionados se o início de um novo negócio é uma opção desejável de carreira, $89 \%$ dos entrevistados brasileiros confirmaram a afirmação, conferindo o $2^{0}$ lugar ao país nesse ranking dentre os 67 países participantes.

A partir de 2012, o relatório GEM passou analisar também a atividade empreendedora nas cinco regiões brasileiras, dado a heterogeneidade $\mathrm{e}$ as regionalidades presentes em um país de grande dimensão como o Brasil. De acordo com o Gráfico 4, a maior taxa TEA foi apresentada pela região Norte, seguida das regiões Sul, Centro-Oeste, Nordeste e Sudeste. A região Nordeste, apesar de apresentar a segunda maior taxa TEA, apresentou taxa total de empreendedorismo inferior à média nacional. Esse resultado indica grande dificuldade dos empreendedores para a manutenção dos seus negócios se comparados com empreendedores de outras regiões.

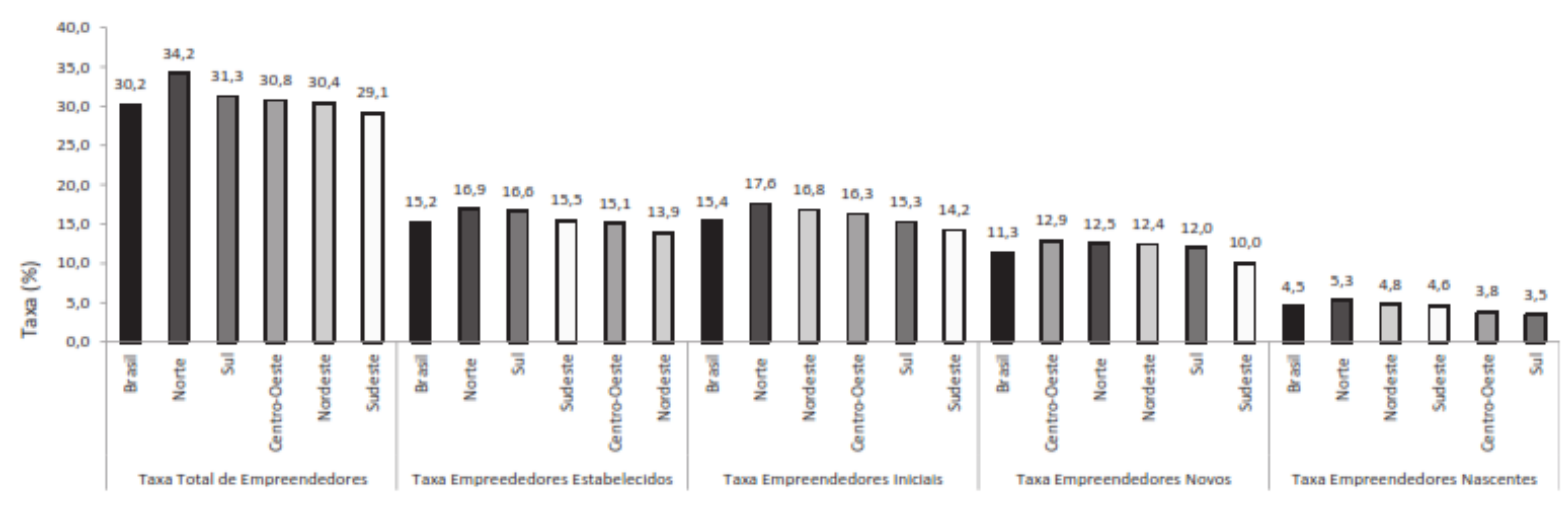

GRÁFICO 4 - Taxa de empreendedores segundo o estágio do empreendimento por região do Brasil - GEM 2012

Fonte: Relatório Executivo GEM-Brasil 2012.

Sobre o perfil do empreendedor brasileiro em 2012, como no ano anterior, a pesquisa revela que os jovens entre 25 e 34 anos de idade apresentam maior taxa de empreendedores iniciais. Destaca-se também que a taxa entre os jovens de 18 a 24 anos é significativamente superior à média de todos os participantes do GEM e da média dos países do grupo efficiency-driven. Esses resultados indicam um alto nível de atividade empreendedora para a parcela jovem da população brasileira.

NOGAMI, V. K. C.; MEDEIROS, J.; FAIA, V. S. Análise da evolução da atividade empreendedora no Brasil de acordo com o Global Entrepreneurship Monitor (GEM) entre os anos de 2000 e 2013. Revista de Empreendedorismo e Gestão de Pequenas Empresas, v. 3, n.3, p. 31-76, 2014. 
Sobre a renda, os resultados brasileiros acompanham a média dos países do GEM, indicando que quanto maior a renda, maior o nível de atividade empreendedora. A mesma relação positiva foi encontrada entre o nível de escolaridade, o TEA no Brasil e na média geral. Quanto maior o nível de escolaridade, maior a atividade empreendedora. Importante ressaltar que esse resultado não é encontrado apenas para altos níveis de escolaridade, mestrado e doutorado, no qual o TEA apresenta o menor valor.

Em relação ao gênero, o Brasil apresentou queda no ranking em relação ao anterior, quanto à taxa de empreendedorismo feminino inicial. A taxa de 14,7\% posicionou o país como $15^{\circ}$ no ranking geral. Entretanto, quanto à taxa de empreendedorismo feminino estabelecido, o país ocupa a 6ำ posição. Sobre a relação entre empreendedorismo do sexo masculino e feminino, para cada 1 empreendedora inicial, o país evidenciou 1,1 empreendedor masculino. Tal relação demonstra certa paridade entre os gêneros e posiciona o país como $10^{\circ}$ nesse ranking.

Um aspecto importante mencionado por especialistas está relacionado ao clima econômico como um fator favorável para a prática empreendedora no Brasil. Uma situação econômica mais favorável, estimula e favorece o empreendedorismo, especialmente o empreendedorismo por oportunidade, diminuindo a percepção de risco. Essa percepção é marcada pela ascensão das classes C e D, o que aumenta o poder de compra da população. Entretanto, essa avaliação favorável não pode ser generalizada a todas as regiões do país, especialmente quanto à região Nordeste.

Como fatores limitantes, os principais destaques foram as políticas governamentais, a falta de apoio financeiro e o baixo nível de educação e capacitação. Quanto ao governo, apesar do destaque positivo dado a políticas como a implantação do Simples Nacional e a criação do Empreendedor Individual, há queixas quanto à complexa e excessiva carga tributária brasileira e a alta burocracia dos órgãos públicos.

Sobre o apoio financeiro, os destaques negativos são para alto custo do crédito e o despreparo do empreendedor frente às exigências bancárias. O último fator já aponta para a falta de capacitação para o empreendedorismo tanto no nível

NOGAMI, V. K. C.; MEDEIROS, J.; FAIA, V. S. Análise da evolução da atividade empreendedora no Brasil de acordo com o Global Entrepreneurship Monitor (GEM) entre os anos de 2000 e 2013. Revista de Empreendedorismo e Gestão de Pequenas Empresas, v. 3, n.3, p. 31-76, 2014. 
superior quanto no ensino do primeiro e segundo grau, destinados a capacitar pessoas para executarem trabalhos como empregados no setor privado.

Brasil no GEM 2013 - 69 países participantes

No ano de 2013, o Brasil melhorou uma posição no ranking do grupo efficiency-driven, constituído de 28 países, atingindo a 8ª posição. Por outro lado, cai uma posição no ranking geral em relação ao ano anterior, se posicionando no 17ํㅜㄴ lugar. Com um TEA de 17,3\%, o Brasil atingiu o segundo maior nível de sua série histórica, atrás apenas da taxa de 17,5\% atingida em 2010.

Considerando a taxa de empreendedores estabelecidos (TEE), o país se apresentou na $4^{\circ}$ posição de seu grupo e na $9^{\circ}$ posição no ranking geral, atingindo um índice de 15,4\%. Em termos absolutos, os índices indicam que em 2013, 40 milhões de indivíduos estavam envolvidos com a atividade empreendedora, sendo 19 milhões na criação ou administração de novos negócios e 21 milhões proprietários ou administradores de negócios estabelecidos. O gráfico 5 apresenta os níveis da TEA e do TEE no período de 2002 a 2013 do Brasil.

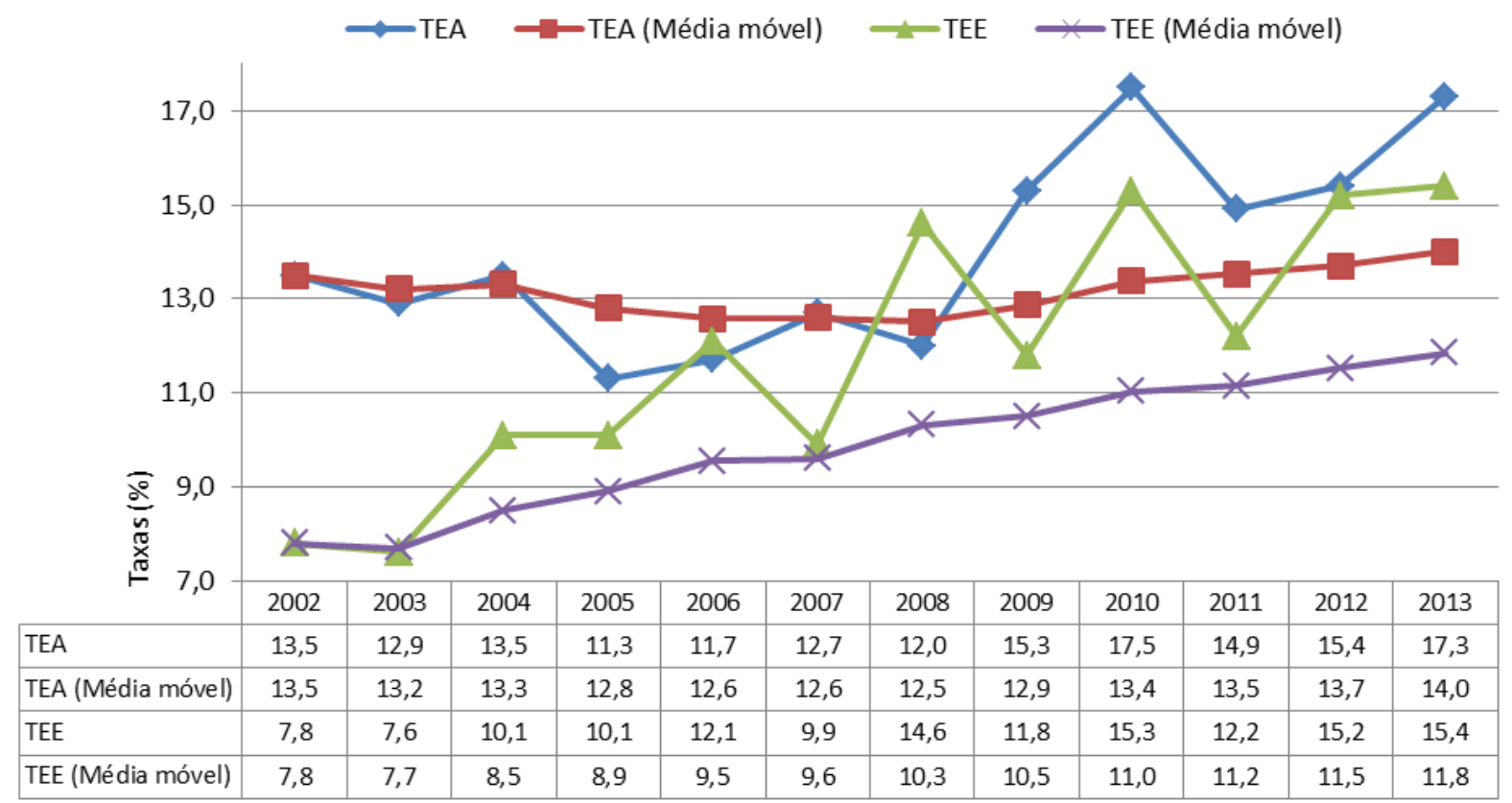

GRÁFICO 5 - Evolução da atividade empreendedora no Brasil segundo estágio do empreendimento Fonte: Relatório Executivo GEM-Brasil 2013.

NOGAMI, V. K. C.; MEDEIROS, J.; FAIA, V. S. Análise da evolução da atividade empreendedora no Brasil de acordo com o Global Entrepreneurship Monitor (GEM) entre os anos de 2000 e 2013. Revista de Empreendedorismo e Gestão de Pequenas Empresas, v. 3, n.3, p. 31-76, 2014. 
Em relação à taxa de empreendedores iniciais (TEA), o relatório destaca o crescimento ocorrido nos últimos 6 anos quando comparado com os demais anos da série. Este fenômeno pode ser percebido analisando não só os níveis anuais da TEA, como também a curva da média móvel apresentada, que indica uma tendência de crescimento consistente a partir de 2009. A média móvel refere-se à média da série histórica de cada ano, ou seja, em 2012, a média refere-se aos valores de 2002 a 2012, enquanto que em 2013, refere-se à média de 2002 a 2013. Por ser uma série histórica curta (12 anos), optou-se pela exclusão de nenhum valor mais antigo da série.

Sobre a taxa de empreendedores estabelecidos, percebe-se uma tendência de crescimento constante, onde o Brasil atingiu o ápice em 2013 com o nível de $15,4 \%$, valor próximo ao dobro do índice atingido em 2002. No ano de 2013, o Brasil atingiu também seu maior índice de empreendedores iniciais motivados a empreender por oportunidade, $71,3 \%$.

$\mathrm{Na}$ análise regional, o relatório indica um crescimento em relação a 2012 na taxa total de empreendedores (TTE) das regiões Centro-Oeste e Sudeste, e uma queda nas regiões Norte, Nordeste e Sul. Desta vez, a taxa total de empreendedores em 2013 foi maior na região Centro-Oeste, seguida da região Sudeste, Norte, Nordeste e Sul. Quanto à motivação para empreender, destaca-se que os maiores índices de empreendedores por oportunidade são os apresentados pela região Sul e Sudeste, enquanto os piores são apresentados pelas regiões Norte e Nordeste, as quais apresentam menor desenvolvimento econômico.

Quanto ao perfil do empreendedor brasileiro em 2013, a respeito do gênero, houve uma inversão na proporção entre homens e mulheres. Enquanto que em 2012 a quantidade de empreendedores iniciais homens era maior, em 2013 o nível foi de $47,8 \%$ em comparação a 52,2\% de empreendedoras. Este fenômeno ocorre em praticamente todas as regiões do Brasil, exceto na região Nordeste, onde a proporção entre homens é ligeiramente maior. De toda a forma, a diferença entre os gêneros se mantém pequena, indicando uma paridade nos níveis.

Como nos anos anteriores, a faixa etária prevalecente entre os empreendedores iniciais no Brasil é entre 25 e 34 anos (33,1\%), fato que se repete

NOGAMI, V. K. C.; MEDEIROS, J.; FAIA, V. S. Análise da evolução da atividade empreendedora no Brasil de acordo com o Global Entrepreneurship Monitor (GEM) entre os anos de 2000 e 2013. Revista de Empreendedorismo e Gestão de Pequenas Empresas, v. 3, n.3, p. 31-76, 2014. 
em todas as regiões do país. Já sobre os empreendedores estabelecidos, a proporção maior é para pessoas que tenham entre 45 e 54 anos (30,4\%). Como no ano anterior, os resultados indicam alto nível de atividade empreendedora para a parcela jovem da população, porém a estabilidade do empreendimento é conquistada mais frequentemente em uma idade mais elevada.

Sobre a escolaridade, destaca-se que o nível de empreendedores iniciais e empreendedores estabelecidos é maior para a parcela de empreendedores com menor escolaridade. $86 \%$ dos empreendedores iniciais no Brasil sequer iniciaram um curso superior. Para empreendedores estabelecidos o número é semelhante, $87,9 \%$.

Na seção em que o GEM consulta especialistas para descrever as condições para empreender no Brasil, é possível identificar que três fatores se destacaram como favoráveis para a atividade empreendedora em 2013: normas culturais e sociais, acesso ao mercado e políticas governamentais. Tais fatores são oriundos da valorização do papel do empreendedor no país pela mídia e pela sociedade em geral, da forte relação existente entre a população em geral e empreendedores, do crescente acesso à informação, do esforço governamental para a simplificação do sistema legal e tributário (Lei Geral da Micro e Pequena Empresa, Lei do Micro Empreendedor Individual, Simples Nacional) e da existência de órgãos de fomento como o SEBRAE.

Entretanto, as políticas governamentais também foram fortemente citadas como fatores limitantes do empreendedorismo, o que evidencia haver muito ainda por fazer para fortalecer a atividade empreendedora como, por exemplo, reduzir a complexidade e a elevada carga imposta pelo Sistema Tributário Nacional, e reduzir também a burocracia das instituições públicas. Outro fator limitante citado é a falta de apoio financeiro e a dificuldade para acesso ao crédito.

O primeiro ponto é o alto custo do crédito no país que limita a capacidade de investimento nos empreendimentos. O segundo ponto está relacionado ao terceiro fator limitante mais citado, baixos níveis de educação e capacitação. O baixo nível de educação é refletido no despreparo dos empreendedores para compreender e atender os requisitos para a obtenção de crédito no sistema bancário. A propósito,

NOGAMI, V. K. C.; MEDEIROS, J.; FAIA, V. S. Análise da evolução da atividade empreendedora no Brasil de acordo com o Global Entrepreneurship Monitor (GEM) entre os anos de 2000 e 2013. Revista de Empreendedorismo e Gestão de Pequenas Empresas, v. 3, n.3, p. 31-76, 2014. 
os especialistas entrevistados defendem um ensino para o empreendedorismo desde o Ensino Fundamental, diminuindo a distância entre o empreendedorismo e a realidade dos alunos.

\section{Análise e discussão dos resultados}

Quanto à evolução da atividade empreendedora brasileira nos 13 anos pesquisados, é possível concluir que há um comportamento constante da atividade, onde o Brasil permanece sempre entre os primeiros colocados no ranking. Em todos os anos, o Brasil obteve uma TEA superior à média de todos os países participantes da pesquisa GEM.

Sabe-se que o crescimento da TEA, em alguns casos, pode ser explicado por um baixo nível de desenvolvimento econômico, o qual incentiva os indivíduos a empreenderem por necessidade. Entretanto este cenário não se aplica ao Brasil que vive em um período recente de um estado de pleno emprego. Esta afirmação é corroborada pelo crescimento do número de empreendedores iniciais que afirmaram ter aberto uma empresa por oportunidade e não por necessidade. O nível de empreendedores por oportunidade passou de 42,4\% em 2002 para 71,3\% em 2013. Além disto, o nível de empreendedores estabelecidos praticamente dobou no período analisado, indicando redução do índice de mortalidade nos anos iniciais do empreendimento.

No quesito gênero, as mulheres, no decorrer dos anos, aumentaram sua participação na atividade, superando, inclusive, o número de homens no ano de 2013. Entretanto, a motivação para empreender é predominantemente baseada na necessidade, já a dos homens, na oportunidade.

Em relação às taxas TEA baseadas na oportunidade e na necessidade também houve inversão de posições durante o período analisado. Como o Brasil é um país pertencente ao grupo efficiency-driven, ou seja, com características emergentes (ainda não são economicamente fortalecidos e estáveis, mas não são considerados frágeis por possuírem potencial de fortalecimento), faz sentido estes índices variarem de acordo com a conjuntura econômica, uma vez que tanto o

NOGAMI, V. K. C.; MEDEIROS, J.; FAIA, V. S. Análise da evolução da atividade empreendedora no Brasil de acordo com o Global Entrepreneurship Monitor (GEM) entre os anos de 2000 e 2013. Revista de Empreendedorismo e Gestão de Pequenas Empresas, v. 3, n.3, p. 31-76, 2014. 
crescimento quanto a fragilização da economia afetam a atividade empreendedora. Mas, como já mencionado, a taxa de empreendedores por motivação tem crescido nos últimos anos.

A propósito, a partir de 2012, o relatório GEM Brasil passou a oferecer também informações específicas para as regiões brasileiras. No ano de 2012, as regiões Norte, Nordeste e Centro-Oeste apresentaram o maior nível de TEA, seguidas da região Sudeste e Sul. Em 2013, a região Sudeste apresentou o maior índice, seguida das regiões Norte, Centro-Oeste, Nordeste e Sul. Por ser uma série histórica pequena, apenas dois anos, poucas conclusões ainda podem ser feitas.

Apesar disto, é possível perceber que as regiões com menor atividade econômica, considerando a participação no PIB nacional, são as que apresentam maior taxa de atividade empreendedora, exceção feita ao nível do TEA apresentado pela região Sudeste em 2012. Este mesmo fenômeno também é percebido nos resultados globais do GEM, nos quais países com pouco desenvolvimento econômico lideram o ranking.

Destaca-se ainda que essas regiões que possuem menor atividade econômica e maior nível de atividade empreendedora possuem níveis menores de empreendedorismo por oportunidade quando comparadas com as regiões Sul e Sudeste.

Sobre o perfil do empreendedor brasileiro é possível destacar a baixa escolaridade. Como apresentado no relatório de 2013, aproximadamente $88 \%$ dos empreendedores brasileiros estabelecidos sequer iniciaram um curso superior. Esse número é refletido na constante citação feita pelos especialistas consultados pelo GEM sobre a falta de educação e capacitação como um fator limitante ao empreendedorismo. A falta de capacitação torna o empreendedor menos preparado para gerir o seu negócio como, por exemplo, cumprir os requisitos exigidos pelos agentes financeiros para captação de crédito. A reversão desse cenário poderia contribuir para melhorar ainda mais os níveis de empreendedores estabelecidos.

Outro ponto a destacar é o papel do governo como facilitador e limitador da atividade empreendedora. O governo passou a sustentar instituições que promovem o empreendedorismo, mas por outro lado exige elevadas taxas tributárias e juros do

NOGAMI, V. K. C.; MEDEIROS, J.; FAIA, V. S. Análise da evolução da atividade empreendedora no Brasil de acordo com o Global Entrepreneurship Monitor (GEM) entre os anos de 2000 e 2013. Revista de Empreendedorismo e Gestão de Pequenas Empresas, v. 3, n.3, p. 31-76, 2014. 
empreendedor. Os relatórios destacam o esforço governamental para favorecer especialmente os micros e pequenos empreendedores, porém a redução da burocratização dos órgãos públicos e da complexidade do sistema tributário pode favorecer ainda mais a atividade empreendedora como, por exemplo, a redução do número de dias para a constituição do negócio.

De qualquer forma, tendo em vista a relação de dependência entre a atividade empreendedora e o crescimento econômico, não foi possível chegar a uma conclusão definitiva. Não se pode interpretar os resultados de uma elevada TEA como uma situação favorável a um desenvolvimento social e sustentável (BRUNEAU; MACHADO, 2006), nem a um cenário econômico fortalecido. Nogami e Machado (2011) também apontam que o teste estatístico de correlação entre a TEA, o PIB e o IDH não possuem uma relação direta entre as variáveis.

Nesse sentido, pode-se dizer que o crescimento econômico influencia positivamente a prática empreendedora (SCHUMPETER, 1984; CÂMARA, 2003; REYNOLDS, 2005; VAN STEL et. al, 2005; WONG, 2005; FONTENELE, 2010), aumentando o poder de compra das pessoas, facilitando o acesso à financiamentos e gerando novas empresas.

Pode-se concluir também, que a desaceleração e a fragilidade de uma economia ocasionam altas taxas de desemprego, fazendo com que as pessoas busquem alternativas de renda, como abrir o próprio negócio (BARROS; PEREIRA, 2008). Assim, uma economia fraca e desacelerada também influencia a atividade empreendedora. Em outras palavras, tanto uma economia forte quanto uma frágil proporcionam um cenário empreendedor.

Nos últimos 13 anos, o Brasil passou por cenários econômicos instáveis e fragilizados. Em um período mais recente, tem se apresentado fortalecido perante a economia global. Uma análise estatística minuciosa pode revelar mais detalhes e apresentar esta relação mais sistematicamente, uma sugestão para pesquisas futuras.

NOGAMI, V. K. C.; MEDEIROS, J.; FAIA, V. S. Análise da evolução da atividade empreendedora no Brasil de acordo com o Global Entrepreneurship Monitor (GEM) entre os anos de 2000 e 2013. Revista de Empreendedorismo e Gestão de Pequenas Empresas, v. 3, n.3, p. 31-76, 2014. 


\section{Considerações finais}

Esta pesquisa teve como objetivo investigar a evolução da atividade empreendedora no Brasil, com base nos relatórios do Global Entreprenership Monitor (GEM), no período de 2000 a 2013. Os principais resultados apontam que em relação a outros países, no período analisado, o Brasil permaneceu com altas e constantes taxas de empreendedorismo.

Apesar disto, as políticas públicas ainda são deficitárias devido a tributos e tempo para abertura dos negócios, fatores que contribuem para a informalidade das empresas. Ademais, mudanças ocorridas na sociedade refletiu em crescimento das mulheres frente a novos empreendimentos. Não obstante isto, os empreendimentos, em tese, têm ocorrido mais pela necessidade e menos pela identificação de oportunidade, com baixa inovação, o que pouco estimula a competitividade e desenvolvimento da economia e mercado.

A partir destas constatações, a pesquisa pode destacar contribuições teóricas para o campo. Primeiramente, a análise dos relatórios do GEM não tem sido explorada pelos pesquisadores, o que pode refletir em dois aspectos: a) em termos metodológicos, a utilização de pesquisa documental, que é pouco aproveitada pela academia; e b) a compreensão da relação entre empreendedorismo e desenvolvimento econômico, que ainda não é exaustiva e apresentam correntes que apontam correlações positivas e negativas entre as duas variáveis.

$\mathrm{Na}$ área de empreendedorismo e desenvolvimento econômico, devido às diversas publicações e relatórios com informações compiladas, apesar de algumas vezes não padronizadas, há oportunidades para pesquisas e desenvolvimento do campo. No entanto, poucos pesquisadores têm explorado o método de pesquisa documental e a utilização de dados secundários.

Por se tratar de pesquisar e entender empresas e perfil dos empreendimentos e empreendedores, o acesso por meio de dados primários torna-se mais restrito. Porém, com a utilização de relatórios disponíveis, foi possível fazer uma análise temporal, compreendendo 14 anos de pesquisa.

NOGAMI, V. K. C.; MEDEIROS, J.; FAIA, V. S. Análise da evolução da atividade empreendedora no Brasil de acordo com o Global Entrepreneurship Monitor (GEM) entre os anos de 2000 e 2013. Revista de Empreendedorismo e Gestão de Pequenas Empresas, v. 3, n.3, p. 31-76, 2014. 
Apesar de intuitivo, não se pode ignorar que o desenvolvimento econômico brasileiro é, em grande parte, refletido por micro e pequenas empresas, as quais geram emprego e renda, levando ao maior consumo dentro da economia de mercado. Isto implica que na esfera governamental, no que tange às preocupações econômicas, a atenção precisa voltar-se para as micros, pequenas e médias empresas. Não apenas questões de tributos e eliminação de papelório que aumentam o tempo e o esforço dispendidos para s abertura dos negócios devem ser destacados, mas também algumas outras sugestões.

O aumento do número de mulheres empreendendo demonstra emergência no atendimento de suas necessidades específicas devido à construção social de seu papel dentro da sociedade. Para elas, as dificuldades são ainda maiores (acesso ao crédito; falta de credibilidade frente a parceiros, clientes e fornecedores; entre outros) e pode acarretar desestímulo e/ou fracasso do empreendimento.

Outro ponto que merece atenção dos dirigentes do país é em relação à educação empreendedora, que envolve além do conhecimento de gerenciamento de empreendimentos, a habilidade de identificar novas oportunidades de negócios. Grande parte da mortalidade das empresas acaba sendo refletida por estes dois fatores. Muitos empreendimentos nascem devido à necessidade e sem o conhecimento das funções administrativas necessárias para o desempenho bem sucedido de uma empresa.

Se observar ainda as áreas da saúde, por exemplo, em sua grande maioria, os profissionais (dentistas, fisioterapeutas, médicos veterinários, nutricionistas, biomédicos, etc.) serão proprietários e dirigentes de empresas (suas clínicas) sem ter a compreensão de como planejar, coordenar, dirigir e controlar os recursos. Quando se dão conta da importância deste conhecimento, precisam buscar instituições privadas (o que é menos estimulante devido aos custos) e muitas vezes já estão na zona da falência. Esta falta de educação empreendedora também reflete em mais empreendimentos por necessidade, uma vez que os proprietários de empresas não compreendem que empreendimentos que apenas reproduzem ou imitam outros dificilmente sobrevivem (BRUYET, JULIEN, 2000), ou seja, faz-se necessário ter um diferencial, inovar.

NOGAMI, V. K. C.; MEDEIROS, J.; FAIA, V. S. Análise da evolução da atividade empreendedora no Brasil de acordo com o Global Entrepreneurship Monitor (GEM) entre os anos de 2000 e 2013. Revista de Empreendedorismo e Gestão de Pequenas Empresas, v. 3, n.3, p. 31-76, 2014. 
Para os empreendedores, esta pesquisa traz como contribuição gerencial a necessidade de buscar educação empreendedora antes de iniciarem seus negócios, o que poderá refletir em permanência mais estável e duradoura dentro do mercado. Atrelado a isto, incentiva-se a atividade empreendedora motivada pela oportunidade com base em inovações nos produtos, empresas, processos e serviços oferecidos. Tal inovação não precisa ser radical ou descontínua, mas de alguma forma precisa destacar os produtos e serviços da empresa frente aos concorrentes, seja na forma de pequenas modificações no produto/serviço, acréscimo de funcionalidade, nova funcionalidade ao produto/serviço, mudança no segmento de mercado e mudança no processo de produção, matéria-prima ou até mesmo redução de custo com a mesma qualidade ou qualidade superior.

A principal limitação do presente artigo foi a falta de padronização dos relatórios do GEM, tanto na apresentação dos dados, quanto no conteúdo do relatório que em determinados anos realizavam algumas análises de indicadores importantes e em outros anos já não os apresentavam. Esta falta de padrão fez com que $o$ trabalho se limitasse apenas aos indicadores que estavam presentes na maioria dos anos da pesquisa.

Outra proposta proveniente da presente pesquisa é relacionar direta e sistematicamente o desenvolvimento econômico com o empreendedorismo, uma vez que crescimento econômico e desenvolvimento econômico não são sinônimos. O crescimento econômico é a ampliação do produto real da economia medido principalmente pelo Produto Interno Bruto (PIB) durante um determinado período de tempo. Este indicador de crescimento não é capaz de mensurar o desenvolvimento econômico de um país, que preza pelo crescimento, mas também por políticas do setor público e privado, capazes de distribuir os benefícios deste crescimento atingindo mais pessoas, diminuindo a desigualdade social de um mesmo país (FEIJÓ, 2007).

Assim, fatores que estão associados ao desenvolvimento econômico são: educação, saúde, taxa de emprego formal, transporte, segurança, entre outros elementos envolvendo a qualidade de vida da sociedade. Portanto, uma relação entre a TEA, o PIB e o IDH seria compreensível para indicar a relação entre o

NOGAMI, V. K. C.; MEDEIROS, J.; FAIA, V. S. Análise da evolução da atividade empreendedora no Brasil de acordo com o Global Entrepreneurship Monitor (GEM) entre os anos de 2000 e 2013. Revista de Empreendedorismo e Gestão de Pequenas Empresas, v. 3, n.3, p. 31-76, 2014. 
empreendedorismo, tanto com o crescimento econômico quanto com o desenvolvimento econômico.

\section{Referências:}

ACS, Z. How Is Entrepreneurship Good For Economic Growth? Innovations: Technology, Governance, Globalization, v. 1, n.1, p. 97-107, 2006.

ALVAREZ, S. A.; BARNEY, J. B. Entrepreneurial Opportunities and Poverty Alleviation. Entrepreneurship Theory and Practice, v. 38, n. 1, p. 159-184, 2014.

BARROS, A. A.; PEREIRA, C. M. M .A. Empreendedorismo e Crescimento Econômico: uma Análise Empírica. RAC - Revista de Administração Contemporânea, Curitiba, v. 12, n. 4, p. 975-993, out./dez. 2008.

BRUNEAU, J.; MACHADO, H. V. Empreendedorismo nos países da América Latina baseado nos indicadores do Global Entrepreneurship Monitor(GEM), v. 24, n.33, p. 18-25, 2006.

DíAZ-CASERO, J. A.; DÍAZ-AUNIÓN, D. A. M.; SÁNCHEZ-ESCOBEDO, M. C. Management Decision, v. 50, n. 9, p. 1686-1711, 2012.

CÂMARA, S. F. Atividade empreendedora e crescimento econômico no Brasil: uma aplicação do modelo de função de transferência. III Encontro de Estudos sobre Empreendedorismo e Gestão de Pequenas Empresas, Brasília. Anais... Brasília: EGEPE, 2003.

CASTRO, B. H. R.; GONÇALVES NETO, C. A Influência do Ambiente Institucional e do Crescimento Econômico sobre o Empreendedorismo: uma Comparação entre Países. In: XXV Simpósio de Gestão e Inovação Tecnológica, 2008. Anais... Brasília: ANPAD, 2008.

FEIJÓ, R. Desenvolvimento econômico - Modelos Evidências, Opções Políticas e o Caso Brasileiro. São Paulo, Atlas, 2007.

FONTENELE, R. E. S. Empreendedorismo, Competitividade e Crescimento Econômico: Evidências Empíricas. RAC - Revista de Administração Contemporânea, Curitiba, v.14, n. 6, p. 1094-1112, nov./dez. 2010.

FONTENELE, R. E. S. SOUSA, P. F. B.; LIMA, A. O. Empreendedorismo, Crescimento Econômico e Competividade dos BRICS: Uma Análise Empírica a partir dos Dados do GEM e GCl. In: XXXV Encontro da Associação Nacional de Pós Graduação e Pesquisa em Administração, 2011. Anais... Rio de Janeiro: ANPAD, 2011.

NOGAMI, V. K. C.; MEDEIROS, J.; FAIA, V. S. Análise da evolução da atividade empreendedora no Brasil de acordo com o Global Entrepreneurship Monitor (GEM) entre os anos de 2000 e 2013. Revista de Empreendedorismo e Gestão de Pequenas Empresas, v. 3, n.3, p. 31-76, 2014. 
GARTNER, W. B.. A conceptual framework for describing the phenomenon of new venture creation. The Academy of Management Review, v. 10, n. 4, p. 696-706, 1985.

GEM 2000. Global Entrepreneurship Monitor: 2000 Executive Report. London: Babson College, 2001.

GEM-Brasil 2001. Global Entrepreneurship Monitor: Empreendedorismo no Brasil. Relatório Executivo 2001. Curitiba: IBQP, 2002.

GEM-Brasil 2002. Global Entrepreneurship Monitor: Empreendedorismo no Brasil. Relatório Executivo 2002. Curitiba: IBQP, 2003.

GEM-Brasil 2003. Global Entrepreneurship Monitor: Empreendedorismo no Brasil. Relatório Executivo 2003. Curitiba: IBQP, 2004.

GEM-Brasil 2004. Global Entrepreneurship Monitor: Empreendedorismo no Brasil. Relatório Executivo 2004. Curitiba: IBQP, 2005.

GEM-Brasil 2005. Global Entrepreneurship Monitor: Empreendedorismo no Brasil. Relatório Executivo 2005. Curitiba: IBQP, 2006.

GEM-Brasil 2006. Global Entrepreneurship Monitor: Empreendedorismo no Brasil. Relatório Executivo 2006. Curitiba: IBQP, 2007.

GEM-Brasil 2007. Global Entrepreneurship Monitor: Empreendedorismo no Brasil. Relatório Executivo 2007. Curitiba: IBQP, 2008.

GEM-Brasil 2008. Global Entrepreneurship Monitor: Empreendedorismo no Brasil. Relatório Executivo 2008. Curitiba: IBQP, 2009.

GEM-Brasil 2009. Global Entrepreneurship Monitor: Empreendedorismo no Brasil. Relatório Executivo 2009. Curitiba: IBQP, 2010.

GEM-Brasil 2010. Global Entrepreneurship Monitor: Empreendedorismo no Brasil. Relatório Executivo 2010. Curitiba: IBQP, 2011.

GEM-Brasil 2011. Global Entrepreneurship Monitor: Empreendedorismo no Brasil. Relatório Executivo 2010. Curitiba: IBQP, 2012.

GEM-Brasil 2012. Global Entrepreneurship Monitor: Empreendedorismo no Brasil. Relatório Executivo 2010. Curitiba: IBQP, 2013.

GEM-Brasil 2013. Global Entrepreneurship Monitor: Empreendedorismo no Brasil. Relatório Executivo 2013. Curitiba: IBQP, 2013.

NOGAMI, V. K. C.; MEDEIROS, J.; FAIA, V. S. Análise da evolução da atividade empreendedora no Brasil de acordo com o Global Entrepreneurship Monitor (GEM) entre os anos de 2000 e 2013. Revista de Empreendedorismo e Gestão de Pequenas Empresas, v. 3, n.3, p. 31-76, 2014. 
GIL, Antonio Carlos. Como elaborar projetos de pesquisa. 4. ed. São Paulo: Atlas, 2002.

GREATTI, L.; PREVIDELI, J. J. O uso do Plano de Negócioscomo instrumento de análise cmoparativa das trajetórias de sucesso e de fracasso empresarial. In:

MACHADO, H. V. (org.). Causas de mortalidade de pequenas empresas: coletânea de estudos. 1. ed. Maringá: EDUEM, 2007. p. 27-51.

HAFER, R. W. Entrepreneurship and state economic growth. Journal of Entrepreneurship and Public Policy, v. 2, n. 1, p. 67-79, 2013.

HOLCOMBE, R.G. Entrepreneurship and economic growth. The Quarterly Journal of Austrian Economics, v. 1, n. 2, p. 45-62, 1998.

JULIEN, P. A. Empreendedorismo regional e economia do conhecimento. Saraiva, 2010.

KARDOS, M. The relationship between entrepreneurship, innovation and sustainable development. Research on European Union countries. Procedia Economics and Finance, v. 3, p. 1030-1035, 2012.

MACHADO, H. V. Identidades de mulheres empreendedoras. Maringá: EDUEM Editora da Universidade Estadual de Maringá, 1.ed, v.1, 2009.

McMULLEN, J. S. Delineating the Domain of Development Entrepreneurship: A Market-Based Approach to Facilitating Inclusive Economic Growth. Entrepreneurship: Theory and Practice, v. 35, n. 1, p. 185-193, 2011.

MEZA, M. L. F. G.; RISSETE, C. R.; CUNHA, S. K.; MACHADO., J. P.; BASTOS JUNIOR, P. A.; GRECO, S. M. S. S. O perfil do empreendedorismo nos países latino-americanos na perspectiva da capacidade de inovação. Revista da Micro e Pequena Empresa, v. 2, n. 2, p. 58-75, 2008.

NOGAMI, V. K C. Análise da Evolução da Atividade Empreendedora no Brasil de acordo com o Global Entrepreneurship Monitor (GEM) entre os anos de 2000 e 2010. In VII EGEPE- Encontro de Estudos Sobre Empreendedorismo e Gestão de Pequenas Empresas, 2012. Anais... Florianópolis: ANEGEPE, 2012.

NOGAMI, V. K. C.; MACHADO, H. V. Atividade Empreendedora nos Países do BRIC: uma análise a partir dos relatórios do GEM no período de 2000 a 2010. Revista da Micro e Pequena Empresa, v. 5, n. 3, p. 114-128, 2011.

NOGAM, V. K. C.; MACHADO, H. V. Análise da Atividade Empreendedora dos Países Ibero Latino Americanos de Acordo com o Global Entrepreneurship Monitor (GEM). Latin American Journal of Business Management, v. 5, n. 1, p. 83-108, 2014.

NOGAMI, V. K. C.; MEDEIROS, J.; FAIA, V. S. Análise da evolução da atividade empreendedora no Brasil de acordo com o Global Entrepreneurship Monitor (GEM) entre os anos de 2000 e 2013. Revista de Empreendedorismo e Gestão de Pequenas Empresas, v. 3, n.3, p. 31-76, 2014. 
PFEIFER, S.; SARLIJA, N. The Relationship between Entrepreneurial Activities, National and Regional Development and Firm Efficiency -- Global Entrepreneurship Monitor (GEM)-based Evidence from Croatia. Journal of Entrepreneurship, v.19, n. 1, p. 23-41, 2010.

PEDROSO, J. P. P.; MASSUKADO-NAKATANI, M. S.; MUSSI, F. B. A relação entre o jeitinho brasileiro e o perfil empreendedor: possíveis interfaces no contexto da atividade empreendedora no Brasil. Revista de Administração Mackenzie - RAM, v. 10 , n. 4 , p. $100-130,2009$.

PONCHIO, M.; ARANHA, F.; TODD, S. Estudo Exploratório do Construto de Materialismo no Contexto de Consumidores de Baixa Renda do Município de São Paulo. In: XXX EnANPAD. Encontro da ANPAD, 2006, Salvador. Anais... Salvador : ANPAD, 2006.

REYNOLDS, P. D. Creative destruction: source or symptom of economic growth? In Z. J. Acs, B. Carlsson, \& C. Karlsson (Eds.), Entrepreneurship, small and mediumsized enterprises and the macroeconomy. Cambridge, UK: Cambridge University Press, p. 97-136, 1999.

REYNOLDS, P.; BOSMA, N.; AUTIO, E.; HUNT, S.; DE BONO, N.; SERVAIS, I.; LOPEZ-GARCIA, P.; CHIN, N. Global Entrepreneurship Monitor: Data Collection Design and Implementation 1998-2003. Small Business Economics, v. 24, p. 205231, 2005.

SANDU, P.; Entrepreneurship in emerging economies: evidence from the global entrepreneurship monitor. Review of Business Research, v. 8, n. 1, p. 161-169, 2008.

SANTOS, J. C.; FALCÃO, D. F. Políticas Públicas e Empreendedorismo no Brasil: Uma Análise do GEM 2006 (Global Entrepreneurship Monitor 2006). In: V EGEPEEncontro de Estudos Sobre Empreendedorismo e Gestão de Pequenas Empresas, 2008. Anais... São Paulo: ANEGEPE, 2008

SAUTET, F. Local and Systemic Entrepreneurship: Solving the Puzzle of Entrepreneurship and Economic Development. Entrepreneurship Theory and Practice, v. 37, n. 2, p.387-402, 2013.

SCHUMPETER, J. Capitalismo, socialismo e democracia. Rio de Janeiro: Zahar Editora, 1984.

SERVIÇO BRASILEIRO DE APOIO ÀS MICRO E PEQUENAS EMPRESAS (Org.). Anuário do trabalho na micro e pequena empresa: 2012. ed. 5. Brasília: DIEESE, 2012. Disponível em:

<http://bis.sebrae.com.br/GestorRepositorio/ARQUIVOS_CHRONUS/bds/bds.nsf/8c b2d324ffde890ece700a5fb073c4da/\$File/4246.pdf>. Acesso em: 15 fev. 2014.

NOGAMI, V. K. C.; MEDEIROS, J.; FAIA, V. S. Análise da evolução da atividade empreendedora no Brasil de acordo com o Global Entrepreneurship Monitor (GEM) entre os anos de 2000 e 2013. Revista de Empreendedorismo e Gestão de Pequenas Empresas, v. 3, n.3, p. 31-76, 2014. 
SHANE, S. Reflections on the 2010 AMR decade award: Delivering on the promise of entrepreneurship as a field of research. Academy of Management Review, v. 37, n. 1, p. 10-20, 2012.

SHANE, S., VENKATARAMAN, S. The promise of Entrepreneurship as a field of research. Academy of Management Review, v. 25, n. 1, p. 217-226, 2000.

SMALLBONE, D.; WELTER, F.; ATELJEVIC, J. Entrepreneurship in emerging market economies: Contemporary issues and perspectives. International Small Business Journal, v. 32, n. 2, p. $113-116,2013$.

SOUZA, E. C. L.; Lopez Júnior, G. S. Empreendedorismo e desenvolvimento: uma relação em aberto. Revista de Administração e Inovação, v. 8, n. 3, p.120-140, 2011.

STERNBERG, R.; WENNEKERS, S. Determinants and Effects of New Business Creation Using Global Entrepreneurship Monitor Data. Small Business Economics, v. 24, p. 193-203, 2005.

TANAS, J. K.; AUDRETSCH, D. B. Entrepreneurship in transitional economy. International Entrepreneurship and Management Journal, v. 7, p. 431-442, 2011.

VAN STEL, A; CARREE, M; THURIK, R. The Effect of Entrepreneurial Activity on National Economic Growth. Small Business Economics, v. 24, p. 311-321, 2005.

WONG, P. K.; PING HO, Y.; AUTIO, E. Entrepreneurship, Innovation and Economic Growth: Evidence from GEM Data. Small Business Economics, v. 24, p. 335-350, 2005.

NOGAMI, V. K. C.; MEDEIROS, J.; FAIA, V. S. Análise da evolução da atividade empreendedora no Brasil de acordo com o Global Entrepreneurship Monitor (GEM) entre os anos de 2000 e 2013. Revista de Empreendedorismo e Gestão de Pequenas Empresas, v. 3, n.3, p. 31-76, 2014. 


\section{Apêndice 1}

Periódicos pesquisa Quali A1: nenhum periódico brasileiro, até esta data, na área de Administração possui essa estratificação.

Periódicos pesquisa Quali A2: Brazilian Business Review (BBR), CERNE (UFLA), Estudos Avançados (USP), Gestão \& Produção (UFSCAR), Opinião Pública (UNICAMP), Organizações \& Sociedade, RAE - Revista de Administração de Empresa, RAUSP-e, Revista Brasileira de Economia, Revista Contabilidade \& Finanças, Revista de Administração Comteporânea, Revista de Administração (FEAUSP), Revista de Economía Mundial Sociologias (UFRGS).

Periódicos pesquisa Quali B1: REAd. Revista Eletrônica de Administração, REAVI - Revista Eletrônica do Alto Vale do Itajaí, Revista Brasileira de Ciências Sociais, Ambiente e Sociedade, Análise Social, Base (UNISINOS), Cadernos de Pesquisa (Fundação Carlos Chagas), Cadernos EBAPE.BR (FGV), Caderno Virtual de Turismo (UFRJ), Ciências Sociais Unisinos, Civitas: Revista de Ciências Sociais, Contexto Internacional (PUCRJ), Economia Aplicada, Economia e Sociedade (UNICAMP), Economia Global e Gestão, Educação em Revista (UFMG), Educação e Pesquisa, Ensaio (Fundação Cesgranrio), Estudos Econômicos), Faces : Revista de Administração (Belo Horizonte), Gestão \& Regionalidade, Informação \& Sociedade (UFPB), Meta: Avaliação, Nova Economia (UFMG), Novos Estudos CEBRAP), Olhar de Professor (UEPG), Produção (São Paulo), RAI : Revista de Administração e Inovação, RAM. Revista de Administração Mackenzie, Revista Brasileira de Ciências Sociais, Revista Brasileira de Gestão de Negócios, Revista Brasileira de Gestão e Desenvolvimento Regional, Revista de Administração da UFSM, Revista de Administração da Unimep, Revista de Ciências da Administração, Revista de Ciências da Administração (CAD/UFSC)

Revista de Economia Contemporânea.

Periódicos pesquisa Quali B2: Análise (PUCRS), Contabilidade, Gestão e Governança Contemporanea (UFBA), Contextus (Fortaleza), Enfoque, Gestão e Planejamento, Internext, Organizações em Contexto, Org \& Demo, Perspectivas Contemporâneas, Pretexto, RACE : Revista de Administração, Contabilidade e Economia, REBRAE. Revista Brasileira de Estratégia, RECADM: Revista Eletrônica de Ciência Administrativa, REGE Revista de Gestão, REMark. Revista Brasileira de Marketing, Revista Alcance, Revista de Gestão e Secretariado, Revista Brasileira de Inovação, Revista Economia \& Gestão, Revista Organizações em Contexto, Revista Pensamento Contemporâneo em Administração (UFF), RGO. Revista de Gestão Organizacional, RGSA: Revista de Gestão Social e Ambiental, S \& G. Sistemas \& Gestão, Sociedade, Contabilidade e Gestão.

Periódicos pesquisa Quali B3: Interface (Natal), Administração em Diálogo, Administração: Ensino e Pesquisa (RAEP), Administração Pública e Gestão Social, Comunicação e Sociedade, Comunicacao, Midia e Consumo, ConTexto, Connexio Revista Científica da Escola de Gestão e Negócios, Contexto (UFRGS), Economia e Desenvolvimento, Estudo \& Debate (UNIVATES), Estudos do CEPE (UNISC), Evidência (UNOESC), Gestão Contemporânea, Gestão e Desenvolvimento, Gestão e Sociedade (UFMG), Gestão.Org, INTERthesis (Florianópolis), In Texto (UFRGS),

NOGAMI, V. K. C.; MEDEIROS, J.; FAIA, V. S. Análise da evolução da atividade empreendedora no Brasil de acordo com o Global Entrepreneurship Monitor (GEM) entre os anos de 2000 e 2013. Revista de Empreendedorismo e Gestão de Pequenas Empresas, v. 3, n.3, p. 31-76, 2014. 


\section{A Revista da ANEGEPE

Navus Revista de Gestão e Tecnologia, Pensar a Prática, Perspectiva Econômica (São Leopoldo), Perspectiva (Erexim), Perspectivas em Gestão \& Conhecimento, Pesquisa e Planejamento Econômico (Rio de Janeiro), Pesquisa Operacional para o Desenvolvimento, RACEF - Revista de Administração, Contabilidade e Economia da FUNDACE, RDE. Revista de Desenvolvimento Econômico, REAVI - Revista Eletrônica do Alto Vale do Itajaí, REBELA - Revista Brasileira de Estudos LatinoAmericanos, Reflexão e Ação, REGEPE - Revista de Empreendedorismo e Gestão de Pequenas Empresas, Revista Administração em Diálogo - RAD, Revista ADM.MADE, Revista ANGRAD

Revista Brasileira de Administração Científica, Revista Ciências Administrativas (UNIFOR)

Revista da Faculdade de Administração e Economia - ReFAE, Revista da Gestão Costeira Integrada

Revista da Micro e Pequena Empresa (FACCAMP), Revista da UNIFEBE, Revista de Administração do Gestor, Revista de Administração e Negócios da Amazônia, Revista de Economia (Curitiba), Revista de Estudos da Comunicação, Revista de Estudos Econômicos, Revista de Gestão, Finanças e Contabilidade, Revista de Negócios, Revista Eletrônica Mestrado em Administração Revista FAMECOS, Revista Fronteiras, Revista Gestão Contemporânea, Rumores. 